\title{
A Decade of Sustainable HCI
}

\section{Connecting $\mathrm{SHCl}$ to the Sustainable Development Goals}

\author{
Lon Hansson \\ Department of Computer and Systems \\ Sciences, Stockholm University \\ Stockholm, Sweden \\ lon@dsv.su.se
}

\author{
Teresa Cerratto Pargman \\ Department of Computer and Systems \\ Sciences, Stockholm University \\ Stockholm, Sweden \\ tessy@dsv.su.se
}

\author{
Daniel Pargman \\ Department of Media Technology and \\ Interaction Design, KTH Royal \\ Institute of Technology \\ Stockholm, Sweden \\ pargman@kth.se
}

\begin{abstract}
Sustainable HCI (SHCI) constitutes a relatively new research field within HCI. We have identified four literature reviews of the field conducted between 2009-2014. In this paper, we present and discuss the results of a systematic literature review of peer-reviewed conference and journal articles that have been published in the field during the last ten years (2010-2019). To this end, we apply the United Nations' Sustainable Development Goals (SDGs) as a framework to classify and discern high-level goals SHCI researchers have worked towards during this period. This paper contributes to HCI by 1) identifying Sustainable Development Goals that SHCI researchers have worked towards, 2) discerning main research trends in the field during the last decade, 3) using the SDG framework generatively to enumerate and reflect on areas that this far have not been covered by SHCI research and 4) presenting takeaways and opportunities for further research by the larger HCI community.
\end{abstract}

\section{CCS CONCEPTS}

- General and reference $\rightarrow$ Surveys and overviews; • Social and professional topics $\rightarrow$ Sustainability; $\bullet$ Human-centered computing $\rightarrow$ Human computer interaction (HCI); HCI theory, concepts and models.

\section{KEYWORDS}

SDG, Sustainable Development Goals, Sustainable HCI, Sustainability, Systematic Literature Review

\section{ACM Reference Format:}

Lon Hansson, Teresa Cerratto Pargman, and Daniel Pargman. 2021. A Decade of Sustainable HCI: Connecting SHCI to the Sustainable Development Goals. In CHI Conference on Human Factors in Computing Systems (CHI '21), May 8-13, 2021, Yokohama, Japan. ACM, New York, NY, USA, 19 pages. https://doi.org/10.1145/3411764.3445069

\section{INTRODUCTION}

Sustainable HCI (SHCI) is a relatively new research field within Human-Computer Interaction (HCI). While sustainability-related

Permission to make digital or hard copies of all or part of this work for personal or classroom use is granted without fee provided that copies are not made or distributed for profit or commercial advantage and that copies bear this notice and the full citation on the first page. Copyrights for components of this work owned by others than ACM must be honored. Abstracting with credit is permitted. To copy otherwise, or republish, to post on servers or to redistribute to lists, requires prior specific permission and/or a fee. Request permissions from permissions@acm.org.

CHI '21, May 8-13, 2021, Yokohama, Japan

(C) 2021 Association for Computing Machinery.

ACM ISBN 978-1-4503-8096-6/21/05 ..\$15.00

https://doi.org/10.1145/3411764.3445069
HCI papers have been published for more than 15 years (e.g., [33], [7], and [45]), the CHI 2007 conference in many respects represented the starting point of systematically thinking about environmental sustainability in the context of HCI. The conference saw the formation of a special interest group (SIG) on Environmental Sustainability and Interaction [63], and a landmark paper by Eli Blevis [9] that coined the term "Sustainable Interaction Design" (SID) and argued that "sustainability can and should be a central focus of interaction design." Much has happened since 2007, but only four literature reviews of the field have been conducted since then: [32], [23], [53], and [21]. In this paper, we present and discuss the results of a systematic literature review of peer-reviewed conference and journal articles that have self-identified as contributing to SHCI during the last decade (2010-2019). Our initial search yielded 182 texts, but after applying various exclusion criteria, we ended up with a corpus consisting of 71 published articles.

This paper does not seek to engage with or define what constitutes sustainability in general or in HCI. Neither do we attempt to evaluate specific technologies or research themes addressed by research in SHCI. Instead, we reflect on the focus of SHCI during the previous decade by mapping the research that has been conducted to the United Nations' 2015 Sustainable Development Goals (SDGs) [22]. The SDGs are used in many different academic disciplines and countries worldwide, and they constitute an established framework covering a spectrum of goals related to environmental, social, and economic sustainability.

The research and design works conducted in the intersection of HCI and sustainability span multiple domains (e.g., food [69], energy [51], water [58]), various perspectives (e.g., Persuasive Computing [91], Green IT [67], Collapse informatics [95], Computing within Limits [68]), different units of analysis (e.g., individual users [13], human practice [78], families [41], communities [18], companies [50]), and a variety of technologies (e.g., ICTs [86], sensors [43], mobile technology [49], etc.). It is, therefore, valuable to reflect on the high-level goals pursued by this research. In this review, we identify these goals through the lens of the Sustainable Development Goals (SDGs). Our results show that the main body of the selected papers in our corpus engages with questions related to one specific SDG. By pointing out goals that have not been explored to any greater extent or not at all, this paper also serves to identify knowledge gaps and opportunities for further research by the SHCI community. Furthermore, we find that a significant amount of work in SHCI cannot easily be mapped to the SDGs. As such, this review also reflects on whether the SDGs constitute a useful framework for 
the SHCI community and what it would entail for the community to adopt this framework.

While this review specifically analyses and discusses work that has self-identified as Sustainable HCI (SHCI), we believe that our approach and findings are valuable to the larger HCI community. The choice to look at the relatively narrow field of SHCI was primarily based on the field's outspoken engagement in sustainability questions, which we hoped would maximise the corpus compatibility with the UN's Sustainable Development Goals (SDGs). There is substantial HCI research (outside of SHCI) that engages with various SDGs without necessarily identifying as sustainability research. We believe that our approach could be used to test other corpora against the SDGs and hope that this review will inspire others to further examine the relation between HCI and the SDGs. The main contributions of this literature review are: 1) identifying Sustainable Development Goals that SHCI researchers have worked towards, 2) discerning main research trends in the field during the last decade, 3) using the SDG framework generatively to enumerate and reflect on areas that this far have not been covered by SHCI research and 4) presenting takeaways and opportunities for further research by the larger HCI community.

\section{RELATED WORK}

The term Sustainable Interaction Design (SID) was coined by Eli Blevis [9] in an article that, in some respects, was the starting point for taking sustainability research seriously within HCI. Three years later, DiSalvo et al. [23] established the term Sustainable HCI (SHCI) in an empirical analysis of a corpus of works that had been published in the intersection between HCI and sustainability. We here regard Sustainable Interaction Design (SID) to be a more narrow and focused research area within the more general umbrella term "Sustainable HCI" (SHCI). While pivotal and important surveys of subsets of the field have explored the role of HCI in the design and evaluation of eco-feedback technologies [30], emerging energy systems and trends in HCI [76], how persuasive technologies are based on a limited framing of sustainability [15] and how current practices of persuasive technologies might reinforce values leading to unsustainable behaviour [54], we have identified four literature reviews conducted of the field covered by SHCI and we shortly summarise these reviews below. The reviews were published between 2009-2014, and they analyse the evolving field of SID/SHCI from different conceptual and methodological perspectives (see Table 1 below).

Drawing on Blevis [9] and Woodruff et al. [101], Goodman [32] performed a discourse analysis of $120 \mathrm{HCI}$ documents from the period 1998-2008 that identified themselves as "environmental HCI". Goodman's work distinguished between three discourses in the intersection of $\mathrm{HCI}$ and environmental issues: "Sustainable Interaction Design," "Revisioning Consumption," and "Citizen Sensing".

One year later, DiSalvo et al. [23] performed a critical analysis on a corpus of 25 programmatic statements (e.g., relevant panel and workshop abstracts or discussions in papers about what SHCI is or should be) and of 58 peer-reviewed journal and conference papers. Inspired by critical theory such as Bardzell's interaction criticism [3], and informed by papers like Blevis' Sustainable Interaction Design [9] and Mankoff et al.'s distinction between "sustainability in design" and "sustainability through design" [63], they asked how "Sustainable HCI" defined itself as a research field [23]. DiSalvo et al.'s [23] work proposed that the field could be characterised by five genres: "Ambient awareness," "Sustainable Interaction Design," "Formative User Studies", "Pervasive and Participatory Sensing" and "Persuasive technology," and they concluded that the latter genre comprised around $45 \%$ of all literature.

In 2013, Knowles et al. [53] used Dryzek's [25] classification of environmental discourses to "...contextualize computing's understanding of, and contribution to, 'sustainability"'. Knowles at al. [53] performed a thematic analysis of 60 papers to develop a holistic framework of questions that have motivated sustainability research in computing. These questions were then tested against two different corpora where the first consisted of the 100 top-cited ACM and IEEE papers related to sustainability. The second consisted of 122 recent papers on computing and sustainability (from the proceedings of the UbiComp, Pervasive, CHI and DIS conferences) covering the time between DiSalvo et al.'s [23] review and Knowles et al.'s [53] review (2010-2012). Out of "ten key questions that, from our analysis, are driving computing's current sustainability research" their analysis showed that Question 4, "How can we use technology to foster environmentally responsible behaviour?", was by far the most dominant research question in both corpora. Furthermore, Knowles et al. [53] suggested that the general conception of sustainability in computing could be mapped onto the three pillars of Sustainable Development (i.e., environmental, social, and economic sustainability - also referred to "the triple bottom line") as outlined in the Brundtland report (1987) [14].

The fourth review was written by Neris et al. [21] in 2014, who performed a critical analysis of $51 \mathrm{HCI}$ papers with a focus on sustainability. The review identified thematic groups and methodological approaches in the research. While Knowles et al. argued for a more holistic perspective on sustainability beyond the triple bottom line [53], Neris et al. [21] instead applied the triple bottom line to analyse their corpus. Neris et al. [21] identified five main "themes" that both differ from, overlap and extend the five "genres" that were identified by DiSalvo et al. [23].

These four literature reviews have contributed to Sustainable $\mathrm{HCI}$ by reflecting on different theoretical standpoints and understandings of sustainability within HCI. They have also been undertaken at different points in time, used different selection criteria, analysed different corpora and used different literature review methodologies (e.g., discourse analysis, critical analysis etc.). As a result, they have categorised SHCI research differently: "three discourses" [32], "five genres" [23], "10 questions" [53], and "five thematic groups" [21]. Several of these categories primarily align research that has been conducted in the field with particular technologies or "hot topics" within HCI such as "citizen sensing," "ambient awareness," "persuasion," "re-visioning consumption," or "living with technology." Unlike these reviews, we do not seek to define sustainability in SHCI or develop a new conceptual framework for classifying SHCI papers through discourses, genres, or themes. We have chosen to be agnostic about issues, particular technologies and methods used. Instead, we have focused on what sustainability challenges the research in question addresses. To this end, we here explore if the well-established framework of the United Nations' Sustainable Development Goals (SDGs) is a useful framework to 
Table 1: Summary of the four literature reviews conducted between 2010 and 2020

\begin{tabular}{|c|c|c|c|c|}
\hline Author & Goodman & DiSalvo et al. & Knowles et al. & Neris et al. \\
\hline $\begin{array}{l}\text { Publication } \\
\text { year }\end{array}$ & 2009 & 2010 & 2013 & 2014 \\
\hline Paper & $\begin{array}{l}\text { Three Environmental } \\
\text { Discourses in Human- } \\
\text { Computer Interaction }\end{array}$ & $\begin{array}{l}\text { Mapping the Landscape of } \\
\text { Sustainable HCI }\end{array}$ & $\begin{array}{l}\text { Exploring Sustainability } \\
\text { Research in Computing: } \\
\text { Where we are and where } \\
\text { we go next }\end{array}$ & $\begin{array}{l}\text { A Systematic Review of Sus- } \\
\text { tainability and Aspects of } \\
\text { Human-Computer Interac- } \\
\text { tion }\end{array}$ \\
\hline Method & Discourse analysis & Critical analysis & Critical reflection & Critical analysis \\
\hline Databases & NSF, IEEE and ACM & $\begin{array}{l}\text { ACM guide to Computing } \\
\text { Literature and snowball ref- } \\
\text { erencing }\end{array}$ & $\begin{array}{l}\text { Corpus 1: ACM and IEEE. } \\
\text { Corpus 2: UbiComp, Perva- } \\
\text { sive, CHI and DIS }\end{array}$ & $\begin{array}{l}\text { ACM, IEEE, Scopus and } \\
\text { Google Scholar }\end{array}$ \\
\hline Corpus & $\begin{array}{l}120 \text { documents on HCI re- } \\
\text { lated to "nature", "the envi- } \\
\text { ronment" or "sustainability }\end{array}$ & $\begin{array}{l}25 \text { programmatic statements } \\
\text { and } 58 \text { peer-reviewed jour- } \\
\text { nal or conference papers }\end{array}$ & $\begin{array}{l}\text { Corpus 1: Top cited papers } \\
(100) \text {. Corpus 2: recent pa- } \\
\text { pers }(122)\end{array}$ & $\begin{array}{l}51 \text { papers on HCI with a fo- } \\
\text { cus on sustainability }\end{array}$ \\
\hline $\begin{array}{l}\text { Period } \\
\text { covered }\end{array}$ & $1998-2008$ & Not mentioned & $2010-2012$ & Not mentioned \\
\hline
\end{tabular}

identify and categorise the different sustainability goals that have been addressed by SHCI research.

We use the year 2010 as a starting point for this literature review. A decade has passed since DiSalvo et al. [23] published their heavily cited landmark paper that coined the term "Sustainable HCI" (SHCI), and no literature reviews covering the field as a whole have been conducted since 2014. Thus, it is high time to analyse what has been published and how the field of Sustainable HCI has developed during the past ten years.

\subsection{The UN's Sustainable Development Goals}

At the United Nations Conference on Environment and Development (UNCED) ${ }^{1}$ in June 1992, more than 178 countries adopted Agenda $21^{2}$, "a comprehensive plan of action to build a global partnership for sustainable development to improve human lives and protect the environment". In September 2000, all 191 member states of the United Nations adopted the precursor to the Sustainable Development Goals - the Millennium Development Goals (MDGs).

The MDGs encompassed eight different goals, and the first goal was to eradicate extreme poverty and hunger by 2015 . Building on the Millennium Declaration, the 2030 Agenda for Sustainable Development and the Sustainable Development Goals was adopted by all member states of the UN in $2015^{3}$. The 17 high-level Sustainable Developments Goals together serve as a shared blueprint for a sustainable vision of the future, and they are represented by

\footnotetext{
${ }^{1}$ See https://sustainabledevelopment.un.org/milestones/unced (accessed 2021-01-12) ${ }^{2}$ See https://sustainabledevelopment.un.org/content/documents/Agenda21.pdf (accessed 2021-01-12)

${ }^{3} \mathrm{~A}$ brief history of the SDGs can be found here: https://sdgs.un.org/goals (accessed 2021-01-12)
}

17 iconic symbols that represent the goals (see Figure 1$)^{4}$. These 17 goals have 169 subgoals ("targets", from now on referred to as "SDG targets") that, in turn, can be broken down into 231 unique indicators. The 17 Sustainable Developments Goals build on and incorporate the three pillars of sustainability (environment, society and economy) and span many different aspects related to sustainability, e.g. social and environmental effects of industry, poverty reduction, gender equality, ensuring access to healthcare for all, conservation of biodiversity etc.

$$
\text { 2020.png }
$$

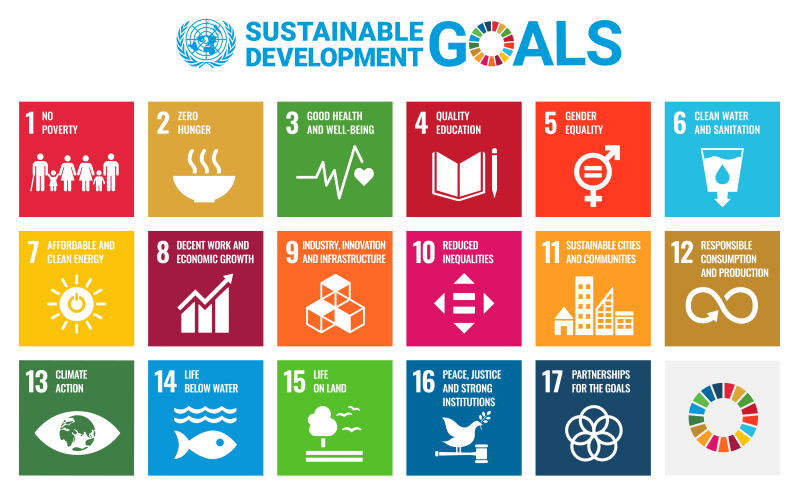

Figure 1: The 17 Sustainable Development Goals.

\footnotetext{
${ }^{4}$ Image downloaded from https://www.un.org/sustainabledevelopment/news/ communications-material/ (accessed 2021-01-12)
} 


\subsection{Connecting the Sustainable Development Goals to Sustainable HCI}

The relation between the SDGs and research works in SHCI was initially explored at the NordiCHI'16 workshop, "HCI and UN's Sustainable Development Goals: Responsibilities, Barriers, and Opportunities" [28]. The workshop asked how SHCI researchers could be inspired by and contribute to the SDGs, and what researchers in SHCI perhaps should do more of. Several authors have also more recently discussed and critically analysed the relationship between HCI and the SDGs ([38], [57] and [59]).

The SDGs are of interest to us since they constitute an established framework that is grounded in global agreements that drive policies and action on local, regional, national, and global levels [6]. In this vein, we have here adopted a perspective that regards sustainability as a global predicament that is made up of a set of interconnected and, at times, contradictory goals that span environmental, social, and economic sustainability. Thus, we have chosen to test if the SDGs can work as an analytical framework that can be used to identify SDGs where much, little or no SHCI research has been conducted during the past decade.

We contrast this with some of the earlier reviews of the field that spent much effort on developing customised analytical lenses that are only applicable to SHCI. When such an analytical lens is based on and tied to specific research or specific HCI trends at the particular point in time when the review was conducted, the lens itself can become outdated and less relevant five or ten years later. This is being said with the greatest respect for the work that has been conducted, but as HCI moves forward, it turns out that the analytical lenses of past reviews are "anchored" in time and hard to reuse of transfer. This choice is also based on our initial attempts at using previously established analytical lenses and methodologies to analyse SHCI research that has been undertaken lately (between 2010-2019). In this context, the SDG framework constitutes a promising and possibly more "durable" instrument, but a question that we explore here is how useful the SDGs are for this specific purpose. A review based on the SDGs also has the potential to bridge or mediate between SHCI research, HCI research that does not self-identify as SCHI and research concerning sustainability outside of HCI.

There are potentially several advantages to using the SDG framework to classify and analyse SHCI research, of which the two most important are:

- The SDGs are a globally accepted framework. Using the SDGs to analyse and classify SHCI research makes it easier to compare and discuss SHCI research to relevant research in other fields and disciplines ${ }^{5}$.

- The SDG framework has subgoals (called "targets" but here referred to as "SDG targets") and measurable indicators that could make future research evaluations within SHCI easier to perform.

\section{METHOD}

Here we explain the methodological choices made for conducting the systematic literature review.

\footnotetext{
${ }^{5}$ Two July 2020 Google Scholar searches for the terms "sustainable development goals" and "SDGs" returned more than 125000 hits each.
}

\subsection{Protocol and Registration}

The structure of this review is based on a combination of Okoli and Schabrams step by step guide to constructing systematic literature reviews [70] and the Preferred Reporting Items for Systematic Reviews and Meta-Analyses (PRISMA) checklist ${ }^{6}$. The PRISMA checklist for systematic literature reviews is a well-established instrument in several disciplines and defines a standardised way to conduct systematic reviews. While adherence to PRISMA is a requirement in many medical journals ${ }^{7}$, adaptions of PRISMA has also been used for systematic literature reviews in HCI (e.g. [98], [34] and [17]).

\subsection{Inclusion Criteria}

This literature review looks at the field of Sustainable HCI (SHCI). As such, we have chosen to include papers that explicitly selfidentify as engaging with and contributing to Sustainable HCI.

3.2.1 Database. The corpus was formed by searching the Association for Computing Machinery (ACM) Guide to Computing Literature. This database contains more than 2.8 million publications and is, according to ACM, "the most comprehensive bibliographic database in existence today focused exclusively on the field of computing"8.

3.2.2 Date of Query. The search was conducted in two steps: an initial search was conducted on August 15, 2019, and a complimentary search was conducted on February 1, 2020. The complementary search exclusively covered the period between August 15 and December 31, 2019.

3.2.3 Search Filter and Date Filter. The search included any result that was published at any time between January 1, 2010, and December 31, 2019, that either used the term Sustainable Interaction Design, Sustainable Human-Computer Interaction or at least one of the term's standard abbreviations (Sustainable HCI or SHCI) anywhere in the paper.

3.2.4 Search Results. A combined search for the terms "Sustainable Human-Computer Interaction", "Sustainable HCI" and "SHCI" yielded 160 hits (texts). These three terms refer to the same concept, and many papers use more than one of these terms. A separate search for the term "Sustainable Interaction Design" (SID) yielded an additional 40 hits. Almost half of these 40 hits referred to papers that also use the term "Sustainable HCI" and these papers had thus already been located. The combined searches resulted in 182 unique texts $(160+22)$.

The decision to include the term "Sustainable Interaction Design" was based on the term's historical relevance and the fact that (as it turned out) many works on Sustainable Interaction Design also self-identify as Sustainable HCI. While it is possible to write a paper about "Sustainable Interaction Design" without referring to Sustainable HCI, we here regard all work on Sustainable Interaction Design to fall under the umbrella term Sustainable HCI through

\footnotetext{
${ }^{6}$ See http://prisma-statement.org/prismastatement/Checklist.aspx (accessed 2021-0112).

${ }^{7}$ See http://www.prisma-statement.org/Endorsement/PRISMAEndorsers.aspx (accessed 2021-01-12).

${ }^{8}$ See https://libraries.acm.org/digital-library/acm-guide-to-computing-literature. (accessed 2021-01-12)
} 
DiSalvo et al.'s [23] genre classification of the field from 2010. A separate search for the acronym "SID" yielded 556 results. We did not further delve into this set of works since the acronym "SID" had more than 30 different meanings related to technology.

\subsection{Exclusion Criteria}

Out of the 182 texts, we excluded works that:

- Were not written in English (3 texts).

- Used the acronym SHCI in another context than "Sustainable HCI" (e.g. "Security in Highly Connected IT Systems" (SHCIS) and "Sexuality and HCI" (SHCI) (11 texts).

- Were not peer-reviewed full papers (e.g. extended abstracts, workshop proposals, posters, book chapters, Ph.D. dissertations). (87 texts).

A total of 81 papers remained after applying these exclusion criteria. After reading each of these 81 papers, an additional ten papers were excluded from the final corpus. While these papers in one way or another referred to sustainability, we deemed that they did not directly engage with sustainability but instead referred to or used sustainability as an argument for discussing something else (e.g. "as apart from Sustainable HCI..."). Our final corpus consists of 71 peer-reviewed papers.

\subsection{SDG Mapping}

We used the Sustainable Development Goals (SDGs) and the SDG targets as a framework for classifying works contributing to the field of SHCI between 2010-2019. Each paper was coded, and metadata was extracted into a shared spreadsheet containing the paper's title, author(s), publication venue, publication year, abstract, keywords, methods, research context (e.g., the home, workplace), research question(s) addressed, and research contribution(s) to SHCI. The first author then screened each paper through a set of questions designed to map the paper to the 17 SDGs and the 169 SDG targets. These questions were:

- Q1. What is the sustainability-related domain addressed by the research?

By domain, we referred to the SDGs' overarching themes: e.g., Energy, Food, Water etc. In cases where the papers did not work with a theme corresponding to the SDGs, the overarching theme of the paper, as stated by the paper, was noted down: e.g., Engagement, Practices, Definitions of Sustainability.

- Q2. What is the sustainability-related subdomain addressed by the research?

By subdomain, we referred to the themes of the SDG targets: e.g. Consumption, Waste, Production etc. In cases where the paper did not correspond to a SDG target, the sustainabilityrelated subdomain, as stated by the paper, was noted down: e.g. Theory, Methods etc.

- Q3 What is the research question(s) addressed in the paper? This question served to identify both the focus and the research contribution of each paper. The information extracted was useful for controlling the accuracy of the mapping made.
Following this procedure, the first author in conversation with the two co-authors sorted and compared the 71 papers in the corpus to each of the 17 SDGs and their 169 targets. This process allowed 51 of the 71 papers in the corpus to be mapped to the SDGs. The remaining 20 papers were not possible to map onto the SDGs. Through the rest of this review, we refer to the two groups of papers as: "the SDG papers" (51 papers) and "the non-SDG papers" (20 papers).

Although many, if not most, of the SDG papers, could feasibly be related to more than one SDG and more than one SDG target, we decided to map each paper in this group to the one SDG and the one SDG target we believe best reflected the paper's overall focus and contribution. One example of this is Hasselqvist and Eriksson's paper [36] which was mapped to SDG target 12.2 "By 2030, achieve the sustainable management and efficient use of natural resources", but could also be argued to belong to SDG target 7.2 "Increase the global percentage of renewable energy" or target 7.3 "Double the improvement in energy efficiency". In this case, the paper was coded as Q1: Energy, Q2: Consumption, and Q3: "...we articulate and discuss more general implications for design aiming to support diverse stakeholder engagement in practices related to resource use", served to verify that the paper's "main" contribution had to do with energy consumption practices. The mapping work was an iterative process where goals and targets were repeatedly reevaluated.

\subsection{Limitations}

In January 2020, ACM launched a new version of its digital library. Depending on whether searches were made before or after January 2020, results could differ. Our initial search was made in August 2019 and since we had performed significant parts of the analysis by January 2020, we chose to only search for recently published papers in our complimentary search that covered the period from August 15, 2019 to December 31, 2019.

Another limitation is that our inclusion criteria clearly missed papers that could have been included in the corpus. We are certainly aware of the fact that there are papers that are situated in the intersection of sustainability and HCI that did not fulfil the inclusion criteria (e.g., did not self-identify by using the specific terms we used in our database search). Such "omissions" represents a side effect of all systematic literature reviews, e.g., some things are included, and some are not included even if they, in some respect, "should" have been included. The first author conducted most of the mapping and clustering of the papers. While all authors discussed any uncertainties that appeared, there is always a risk of errors and misinterpretations.

\section{RESULTS}

All results in this section are based exclusively on analyses of the 71 papers in the corpus. First, this section unpacks the results of the systematic literature review by characterising the corpus of works included in this study. Second, we present the results of mapping the corpus onto the SDGs and the SDG targets, including the fact that it was only possible to do so for 51 of the 71 papers (the SDG papers). Third, we summarise areas that SHCI researchers have engaged with during the last ten years. Fourth, we describe and 
discuss the 20 SHCI papers that were part of the corpus but could not be mapped onto the SDG framework (the non-SDG papers).

\subsection{The Corpus}

This section presents the venues where the selected papers were published and their distribution over time. The inclusion and exclusion criteria are further described in the method section (above).

Out of the 71 SHCI papers in our corpus, we found that year 2012 was the one year when the largest number of papers were published (11 papers), followed by 2013 (10 papers). In 2014, the number of publications fell back, but has since stabilised around 7-9 papers per year (see figure 2). The papers in our corpus were published at no less than 20 different venues, and only three of these were journals. The most popular of the journals was the ACM Transactions on Computer-Human Interaction (TOCHI) with six publications. The two journals, Personal and Ubiquitous Computing and the International Journal of Human-Computer Studies, had one publication each. The other 17 venues were all conferences, of which the ACM CHI Conference on Human Factors in Computing Systems (CHI) was the single most popular venue with 26 publications (37\% of the corpus). The second and third most popular conferences were the ACM conference on Designing Interactive Systems (DIS) with ten publications (14\% of the corpus) and Computing within Limits (LIMITS) with six publications (8\%).

The following section will further analyse the SDG papers. The non-SDG papers will be covered more in-depth at the end of the results section.

\subsection{The SDG Papers}

As mentioned earlier, 51 out of the 71 papers in the corpus were mapped onto the 17 Sustainable Development Goals (SDGs), and these papers were unevenly distributed among 6 of the 17 SDGs. 42 of these 51 papers were mapped to SDG 12, "Responsible Consumption and Production." The other 5 SDGs represented by papers in the corpus were SDG 2, "Zero Hunger" (2 papers), SDG 7, "Affordable and Clean Energy" (1 paper), SDG 9, "Industry, Innovation and Infrastructure" (1 paper), SDG 11, "Sustainable Cities and Communities" (3 papers) and SDG 13, "Climate Action" (2 papers). 11 of the 17 SDGs (e.g. two-thirds) were not addressed by any paper in the corpus.

By visualising the spread of the 51 SDG papers over time (see Figure 3), we can see a sustained interest in the topics covered by SDG 12, "Responsible Consumption and Production", throughout the whole period (2010-2019). We find it challenging to discuss trends among or between the different SDGs since the distribution is skewed and an overwhelming majority of the papers are mapped onto a single SDG. Still, the results indicate that SDG 11, "Sustainable Cities and Communities", might be a future topic in Sustainable HCI.

The 17 SDGs has between 5-19 targets each for a total of 169 targets. SDG 12 has 11 targets, and the 42 papers that were mapped onto SDG 12 were matched onto 5 of these targets. The remaining 9 SDG papers were distributed among 6 other targets (see Table 2 below). The full distribution of the 51 papers between the different SDGs and their targets can be seen in Table 2 below.

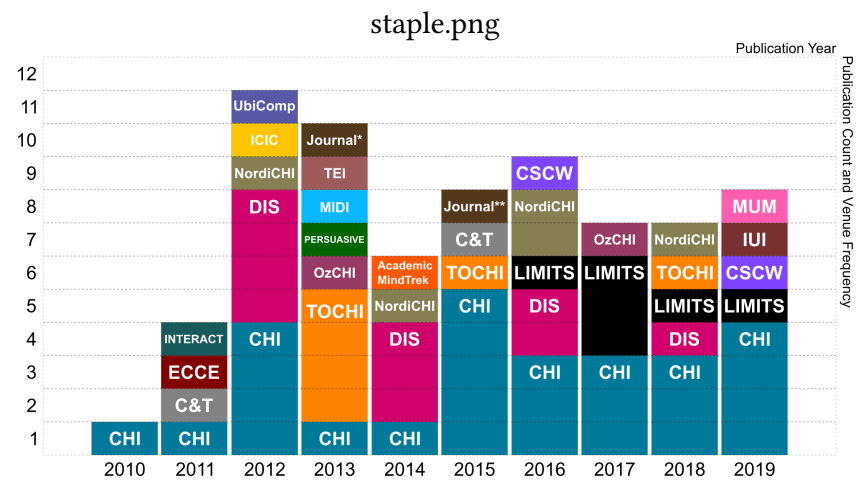

Figure 2: Publications by year and venue between 2010 and 2019. The colors in this figure were chosen to be distinguishable and do not represent the venues. $\mathrm{CHI}$ : Conference on Human Factors in Computing Systems. INTERACT: International Conference on Human-Computer Interaction. ECCE: European Conference on Cognitive Ergonomics. C\&T: Communities and Technologies. UbiComp: Ubiquitous Computing. ICIC: International Conference on Intercultural Collaboration. NORDICHI: the Nordic CHI. DIS: Designing Interactive Systems. ${ }^{*}$ Personal and Ubiquitous Computing. TEI: Tangible, embedded and embodied interaction. MIDI: Multimedia, Interaction, Design and Innovation. Persuasive: International Conference on Persuasive Technology. OzCHI: Australian CHI. TOCHI: Transactions of CHI. Academic Mindtrek: International Academic MindTrek Conference. ${ }^{* *}$ International Journal of Human-Computer Studies. CSCW: Computer-Supported Cooperative Work \& Social Computing. LIMITS: Computing within Limits. MUM: Mobile and Ubiquitous Multimedia. IUI: Intelligent User Interfaces.

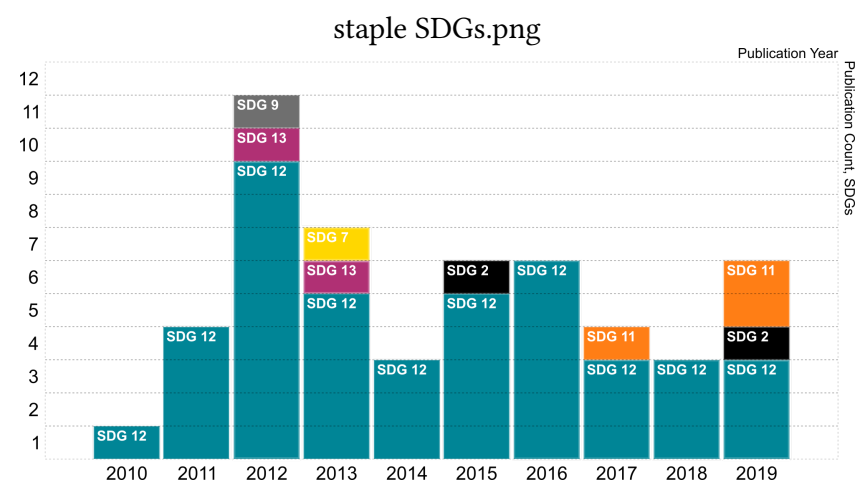

Figure 3: The 51 papers in the SDG corpus, depicted by SDG mapping and publication over time. The colors in this figure were chosen to be distinguishable. While the SDGs have different colors (see fig 1), many of them are hard to tell apart. As such, the colors representing the SDGs in this figure were not transposed from the SDGs.

Of the 42 SDG papers mapped to SDG 12, "Responsible Consumption and Production", 26 papers were mapped to target 12.2, 
Table 2: The SDG corpus mapped to six SDGs and 11 SDG targets.

\begin{tabular}{ll}
\hline SDG & SDG Target \\
\hline 2: Zero Hunger & $\begin{array}{l}\text { 2.4: By 2030, ensure sustainable food production systems and implement resilient agri- } \\
\text { cultural practices that increase productivity and production, that help maintain ecosystems, that } \\
\text { strengthen capacity for adaptation to climate change, extreme weather, drought, flooding and other } \\
\text { disasters and that progressively improve land and soil quality. }\end{array}$ \\
\hline
\end{tabular}

7: Affordable and 7.1: By 2030, ensure universal access to affordable, reliable and modern energy services. Clean Energy

9: Industry, Innova- 9.1: Develop quality, reliable, sustainable and resilient infrastructure, including regional and 1 tion and Infrastruc- transborder infrastructure, to support economic development and human well-being, with a focus ture on affordable and equitable access for all.

11: Sustainable cities 11.3: By 2030, enhance inclusive and sustainable urbanization and capacity for participatory, 1 and communities integrated and sustainable human settlement planning and management in all countries.

11.6: By 2030, reduce the adverse per capita environmental impact of cities, including by paying 2 special attention to air quality and municipal and other waste management.

12: Responsible con- 12.2: By 2030, achieve the sustainable management and efficient use of natural resources. 26 sumption and production

12.3: By 2030, halve per capita global food waste at the retail and consumer levels and reduce 1 food losses along production and supply chains, including post-harvest losses.

12.5: By 2030, substantially reduce waste generation through prevention, reduction, recycling 12 and reuse.

12.6: Encourage companies, especially large and transnational companies, to adopt sustainable 1 practices and to integrate sustainability information into their reporting cycle.

12.8: By 2030, ensure that people everywhere have the relevant information and awareness for 2 sustainable development and lifestyles in harmony with nature.

\section{3: Climate Action}

13.1: Strengthen resilience and adaptive capacity to climate-related hazards and natural disas- 2 ters in all countries. “...sustainable management and efficient use of natural resources" and 12 papers were mapped to target 12.5 , “...reduce waste generation". Out of the 51 SHCI papers mapped onto the SDGs, more than $80 \%$ connected to a single SDG (SDG 12 ), and more than $70 \%$ of these 51 papers were matched onto only 2 of the 169 SDG targets. This implies that many issues covered by the SDGs have hardly or not at all been explored by SHCI research, something we will return to in the discussion.

While we have chosen to use the SDGs and the SDG targets for classification purposes instead of terms like "discourses" or "genres", the fact that a large majority of the papers (38 papers) were mapped to only 2 of the 169 SDG targets (12.2 and 12.5) have forced us to partly reconsider. In the following discussion, we further analyse how the papers in our corpus have engaged with the 2 major SDG targets during the last decade. For narrative purposes in this discussion, we have chosen to group the papers. The grouping builds on DiSalvo et al. [23], who identified emergent clusters of research that "draw from similar sources, share a general problem formulation, and have similar ideas of how to approach solving those problems." (p. 1977).

All references in the following analysis refer exclusively to the 71 papers in our corpus. See the appendix for a more detailed overview of these papers.

4.2.1 SDG target 12.2: By 2030, achieve the sustainable management and efficient use of natural resources. Out of the 51 papers in the SDG corpus, more than half (26 papers) engaged explicitly with SDG target 12.2. We discuss these 26 papers below and have divided them into three groups based on how they approach questions related to the target. The first group (18 papers) consists of papers about eco-feedback and eco-visualisation systems. The second group (5 papers) discusses the environmental impacts of digital 
infrastructures. The third group consists of three papers that discuss thermography and energy leaks.

Eco-feedback Systems. Out of the 26 papers mapped onto SDG target 12.2, a majority (18 papers) concerned so-called eco-feedback or eco-visualisation systems that visualise and provide feedback about resource use. Most papers treated one particular resource, namely energy. All papers explore individuals' everyday resource use (e.g [20]), with the exception of three papers that instead look at resource use beyond the domestic setting ([102], [103] and [35]). Yun et al. [102] chose to examine the potential of persuasive systems to prompt energy-saving behaviours in the workplace, and Zapico et al. [103] studied how automatic data gathering (from a chain of grocery stores) could be used to provide consumers with detailed information about their purchase patterns of organic foods. Hasselqvist et al. [35] have explored how (amateur) energy managers in Swedish housing cooperatives (often with 100 apartments or more) can save energy in the buildings they manage and how they can learn from each other.

Critique of persuasive systems was not uncommon in these papers. One prominent paper argues that "persuasion is based on a limited framing of sustainability, human behaviour, and their interrelationship" and states that the assumption that individuals will act reasonably and responsibly if only provided with enough information is in itself questionable [16]. Many of the SDG papers written between 2010-2014 paired concepts from behavioural psychology with novel technological systems (e.g., eco-feedback or eco-visualisation systems) to influence the individual's behaviours. Papers that were critical of this approach pointed to flaws in the standard design approaches used to "engineer" behaviours and the need to re-evaluate the theories that underpin the mechanisms for realising behaviour change [55]. By advocating for a shift from behaviours to practices, it was also stressed that systems made to negotiate everyday life should be designed to fit the already-existing practices of the people who will use the systems [90]. While there has been an increased emphasis on practices over behaviours during the last decade, both perspectives have continued to be present and co-exist in the papers of our corpus.

Research about nudging or negotiating individuals' resource consumption through computing have suggested that personalised eco-feedback systems that are based on users' value orientations can be used to persuade in the direction of preferred behaviour changes (e.g. to decrease consumption and save resources) [74]. Other papers have explored the potential of using social influences to nudge the individual's consumption patterns. Such studies have demonstrated that eco-feedback can be strengthened through social ties (e.g. social pressure from family members) [4], and that ecofeedback results can be compared between users to trigger their motivation [75]. Promoting cooperation between people has also been shown to have an impact on individual energy consumption behaviours in the home [11].

With a focus that looks beyond the individual, it has been acknowledged that the individual's resource use can be influenced by many stakeholders, and that including these stakeholders in the design process can open up new design opportunities for supporting sustainable practices [36].
In 2010, Pierce et al. [77] proposed that resource use could be shifted to off-peak hours through various technologies. This idea has been investigated by Jensen et al. [46] who examined how visualising energy costs can be used to shift energy consumption from peak hours, and how provocative designs can be used to challenge the idea that renewable energy is an always-available resource, in order to understand energy-consuming practices in the home [48]. Rasmussen et al. [82] instead explored the potential for more flexible everyday practices and the socio-technical challenges associated with shifting resource consumption in time. The sociotechnological challenges of shifting resource consumption in time have also been explored in the context of Smart Home Energy Management Systems (SHEMS) [96] and by examining how timeshifting that is assisted by automation is experienced in everyday life [47].

Environmental Impacts of Digital Infrastructure. Research that explores the environmental impacts of (complex large-scale) digital infrastructure often draws on or expands the principles of Sustainable Interaction Design (SID). This perspective tends to place the responsibility for sustainable management and efficient use of natural resources on (Internet) providers and developers rather than on the individual. As work in HCI and related computing research areas for the most part work towards developing new innovative technologies, there is often a lack of awareness of the impacts these technologies may have on the environment. The need to understand such impacts has thus been highlighted by SHCI research (e.g. [5]). By exploring how a variety of daily practices has come to build and depend on high bandwidth and data traffic, it has been proposed that applications, services and infrastructures for smartphones and tablets should be (re)designed around the principles of 'light-weight' data to reduce the environmental harm caused by the manufacture and use of digital artefacts ([62]). By critically applying Sustainable Interaction Design principles to cloud services' use of and demand for an ever-growing digital infrastructure, Priest et al. [79] suggest that the current design paradigm creates a reinforcing feedback loop and a cornucopian paradigm that does not acknowledge environmental limits. Blevis et al. [10] have synthesised and connected frameworks from Sustainable Interaction Design (SID) and Sustainable Digital Infrastructure Design (SDID). By expanding the principles of SID (as formulated in 2007), it has also been shown that the framework not only can contribute to making interaction design more sustainable, but that SID principles also can be applied to corporate greenhouse gas reduction strategies [80].

Thermography and Energy Leaks Detection. The remaining three papers are all related to the use of thermal cameras to detect energy leaks [64, 66] and automated thermography for energy auditors [65]. This research is focused on detecting energy leakages in housing insulation in order to better optimise the insulation of buildings.

4.2.2 SDG target 12.5: By 2030, substantially reduce waste generation through prevention, reduction, recycling and reuse. Out of the 51 papers in the SDG corpus, 12 papers engaged specifically with questions related to SDG target 12.5, which states that we should substantially reduce waste generation by 2030 . We discuss these 12 papers below and have divided them into three groups. The first group discusses how e-waste can be reduced by prolonging the life 
of artefacts and designing artefacts in ways that make people want to hold on to them longer. The second group explores how e-waste can be reduced through re-use and Do-It-Yourself (DIY) practices. The third group, "other", encompasses papers that deal with the reduction of waste in the form of food, how fashion can be used as a positive force for sustainable choices, and how historical artefacts can inform alternative conceptions for the design of computational devices. All three groups contain four papers each.

Longevity and Personal Attachments to Artifacts. One approach for reducing e-waste generation is to find ways of designing artefacts that prolongs their expected life. Longevity in this context refers both to physical longevity of the artefact itself and to design artefacts in ways that counter consumers' tendency to (too) quickly replace artefacts that function with newer versions, e.g. to design to encourage personal attachments to artefacts. Building on the idea that design could help maintain appeal over time and cause artefacts to achieve heirloom status, Turner \& Turner [97] showed that there are no distinctions between emotional attachments to digital artefacts versus non-digital artefacts. As an initial step to bridge the theory-practice gap of personal attachments in artefact ownership, research has explored how personal attachments can be integrated into the design process and design thinking of professional designers [31]. Challenges involved in communicating such frameworks to practitioners have been underscored by Remy et al. [85]. Work on longevity is also rooted in the assumption that prolonged use of software has effects on the longevity of hardware. Designing for appropriation has therefore been promoted as a means to encourage renewal and reuse of software and hardware artefacts [1].

Re-use and DIY practices. Papers in the SDG corpus also explored ways of reducing waste generation, e.g. through re-use and DIY practices. Vyas [99] show how religious beliefs, traditions, family intimacy, personal interests and health issues all are incorporated into the appropriation, adaptation and repurposing of domestic artefacts to support household members' everyday activities (e.g. how a pair of old jeans can be repurposed as a bag). Bowser et al. [12] explored the shifting or transferral of artefact ownership as an example of re-use by examining secondhand shoppers' practices and motivations. Looking at everyday repair and DIY practices, Wakkary et al. [100] argued for understanding the dynamics of practices as a starting point to redefine Sustainable Interaction Design (SID) and that sustainable interaction designers should codesign together with DIY-enthusiasts, which would include making use of transparent, open strategies and accessible materials. Further exploring SID, Roedl et al. [87] highlighted the opportunities and limitations provided by DIY practices and the rhetorical shift from "users" to "makers", "crafters" and "hackers" in relation to the challenges of countering planned obsolescence.

Other. Some researchers have explored the use of persuasive technologies in the context of reducing waste and in particular as a means to motivate reflection and behavioural change in relation to habits pertaining to food waste and recycling. In this context, Thieme et al. [93] uncovered that the use of normative social influences as a motivator for change could evoke feelings of guilt for behaviours that deviated from the preferred norm. Comber \&
Thieme [19] showed that designing for conscious reflection on intentions and behaviours relating to food waste disposal can trigger self-reflection and re-evaluation of the individual's behaviour. Furthermore, Pan et al. [72] set out to re-conceptualise fashion as a positive force for reducing waste generation by making sustainable alternatives fashionable. Fernaeus et al. [29] question concepts of physicality and materiality in modern computing by looking at how interaction design can be informed by design qualities of historical tools, crafts and practices.

\subsection{The Non-SDG Papers}

The non-SDG corpus consists of 20 papers that could not be mapped to the SDGs (and the SDG targets). These 20 papers could be further divided into two groups, with 10 papers in each group. The first group consists of papers that analyse, criticise and reflect on SHCI as an area of research and design within HCI, including what direction SHCI is or should be taking. The second group consists of papers that do work with sustainability questions, but that were hard to map to the SDG framework. We briefly discuss these two groups of papers below.

The first group of papers is focused on an internal dialogue related to SHCI as a research field (e.g. definitions of sustainability, theoretical perspectives, methods, concepts, evaluations etc.). Pargman and Raghavan [73] leveraged ecological thinking from disciplines outside of computer science. They questioned whether the body of work in SHCI adhered to any meaningful definition of sustainability and proposed that the community should rethink its definition(s) of sustainability. Acknowledging that it can be challenging for practical work in HCI to respond to such calls to arms, Raghavan and Pargman [81] proposed that the design rubric of disintermediation could be adopted within $\mathrm{HCI}$ as a means to reach more holistic perspectives.

It has also been suggested that the SHCI community needs better and more convincing ways to evaluate and communicate sustainability solutions [84]. Building on the need for evaluating SHCI solutions, Remy et al. [83] defined key elements for identifying appropriate evaluation methods that could be used to discuss current and future evaluation practices in SHCI research. While a lack of a clear set of aims and metrics has been highlighted as an impediment for progression in the field, Knowles et al. [52] argue that substantive progress has been made by comparing older categories of work with more recent developments in SHCI.

Thomas et al. [94] argue that Human-centered design (HCD) ignores the broader environmental and socio-political effects of digital technologies and that it is inappropriate to place human wants at the centre of design decisions when those wants have created an impending climate crisis. Adopting the idea that we should work with nature instead of against it, the philosophy of permaculture has been proposed as an alternative to the "correction and control" paradigm reflected in persuasive systems [60]. Further work by Liu et al. [61] explore possibilities for the design space of technological interventions working with nature by looking at non-traditional users and interactions between humans and other species. Egan et al. [26] approach the philosophy of permaculture from another angle and argue that our thinking and doing in HCI can be shifted by employing a blended space perspective to permaculture, university 
campuses and digital media. Drawing on yet other philosophies, Pan \& Blevis [71] examined possible design opportunities in SHCI though the concept of fashion thinking.

The second group of papers have worked with research on topics related to sustainability that we could not map to the SDGs. The problem here is not that these papers have been misclassified, erroneously self-identify as SHCI papers or do not engage with sustainability issues. We have read these papers and can ascertain that sustainability is central to these papers (but further see the Discussion below). However, we have also noticed that the way sustainability is defined and operationalised through the SDG framework makes it difficult to match these papers to any particular SDG out of the 17 SDGs that are available. There is, in other words, a mismatch between the topic of these papers and the Sustainable Development Goals. This mismatch points at a possible weakness of the SDG framework as an analytical lens in our field and for our purposes (further see the Discussion below).

Håkansson \& Sengers $[41,42]$ showed that using ICTs to support sustainability is not unproblematic since they can both help and disrupt environmentally sound lifestyles and practices. Heitlinger et al. [39] pointed out that it is essential to understand the practices, needs and values of the people who are intended to use the technologies if we are to design tools that can support socially and environmentally sound practices of communities. Other research discussed how technologies could create opportunities that support the transition to sustainable practices in the context of car-free living [37] and the role of ICTs in supporting and scaling up local sustainability-oriented organisations' work towards social change and the establishment of more sustainable practices [8].

The focus on everyday practices has shown promise, and Entwistle et al. [27] asked how shared practices can be put into concrete use in teams that are unfamiliar with the practice orientation. To that end, they developed a framework, The Contextual Wheel of Practice to ease knowledge transfer and facilitate collaboration between team members of different disciplines. Kuijer et al. [56] interpreted practice-oriented design approaches as a body performance and have suggested a Generative Improve Performance approach as a way to conceptualise change on a practice level.

Other studies that are related to sustainability but could not be mapped to the SDGs have focused on how SHCI can borrow expressions from popular culture to communicate challenges and potential sustainability solutions to a broad public audience [92]. Further work in this area has explored possibilities of using interactive art as a means for expressing and communicating questions [44], as well as how the enabling and constraining of participation caused by these expressions also reflect challenges in the field of HCI [40].

\section{DISCUSSION}

Our initial attempts at this systematic literature review aimed to re-map the field of Sustainable HCI. It involved looking at previous literature reviews in the field in order to reuse, restyle or remake previously defined "discourses", "genres" or "themes" that have been used to classify and reflect on SHCI work in the past. Practical problems however ensued as we realised that the field had changed over the last decade and that previously suggested frameworks to some or to a large extent reflected the period when they were defined (for example by using specific then-popular methods or technologies as categories). Instead, we chose to analyse the field by using a framework that comes from outside of SHCI, the Sustainable Development Goals (SDGs). So, how well has this framework served us in our endeavour?

From the analysis conducted, we do believe that the SDG framework does work for the purpose of identifying SDGs or "high-level goals" that SHCI researchers have worked towards, and that the SDGs themselves can represent a useful way of operationalising sustainability. The numerous SDG sub-goals (so-called "SDG targets") help further define and classify what goals SHCI researchers have worked towards in their research. The fact that only 51 of the 71 papers in our corpus $(70 \%)$ could be matched to the SDGs could be considered a weakness, but there are mitigating circumstances (see below).

The SDG framework has also helped identify main research trends in the field of SHCI during the last decade. Of the 51 papers that could be mapped to the SDGs, no less than 42 papers were mapped to one particular SDG, namely SDG 12, "Responsible Consumption and Production". At the level of SDG targets, 36 of these 42 papers were mapped to two particular SDG targets, namely SDG target 12.2 ("By 2030, achieve the sustainable management and efficient use of natural resources", 26 papers) and SDG target 12.5 ("By 2030, substantially reduce waste generation through prevention, reduction, recycling and reuse", 12 papers). These were the only 2 of the 169 SDG targets that had more than 2 papers mapped to them (see table 2 above). The remaining 9 SHCI papers were mapped to 5 different SDGs (with 1-3 papers per SDG).

Is it then possible to state that the 11 SDGs where no research at all has been conducted, or that the 5 SDGs where only 1-3 papers were written between 2010 and 2019 have been neglected by the SHCI community? We do not think it is possible to draw that conclusion for two reasons. The first is that it could be the case that $\mathrm{HCI}$ is more or less relevant and applicable to some, rather than to other SDGs. It is, for example, a challenge to see how HCI could substantially contribute to SDG 14 , Life under water ("Conserve and sustainably use the oceans, seas and marine resources for sustainable development"). We do not mean to say that it is impossible to imagine that SHCI could ever contribute to SDG 14, but we do say that compared to other SDGs, we believe there is less of a match between this specific goal (SDG 14) and the methods and tools that $\mathrm{HCI}$ researchers have at their disposal.

The second reason is that there is much HCI research that could be construed as working towards particular SDGs, but without self-identifying as Sustainable HCI. This is obviously the case for research that for example could be classified as working towards SDG 3, "Good health and well-being", or SDG 4, "Quality education", and for papers in the intersection of HCI and ICTs for Development (ICTD), including $\mathrm{HCIxB}^{9}$ (HCI across borders, see further Kumar et al. [57]). We also know there exists research that is related to sustainability, and that uses the term "sustainability", but that has been omitted from this literature review for failing to self-identify as Sustainable HCI research (e.g. for failing to use specific terms such as "Sustainable HCI" or "Sustainable Interaction Design", see

\footnotetext{
${ }^{9}$ see https://www.hcixb.org (accessed 2021-01-12)
} 
further Inclusion criteria above). Despite these kinks, we think that the SDGs and the SDG targets can be used generatively, for example as a checklist, to come up with areas and problems where SHCI research could but has not yet contributed to any larger extent.

\subsection{Complications with classifications}

An issue that might be confusing is that there are examples of research that uses the same theories and methodological frameworks, but that end up being matched to different SDG targets. Some papers that use the Sustainable Interaction Design (SID) framework are, for example, matched to SDG target 12.2 while other papers are matched to SDG target 12.5. Papers that are matched to SDG target 12.2 use SID as a lens to analyse responsible design and production of the digital infrastructure. In contrast, papers that are matched to SDG target 12.5 use the SID framework to reduce the waste generated by artefacts and designs. Another example is practice theory [88]. Research in SHCI that uses a practice theory framework often aims at understanding how we can design for more sustainable practices and use this perspective to support the argument that $\mathrm{HCI}$ researchers and system designers need to understand the everyday realities of the end-users of digital artefacts. As such, the framework has been applied to a variety of work focusing on the social aspect of technology.

\subsection{Are the SDGs too narrow?}

While the 17 SDGs are broad, it is also possible to find works that engage with sustainability, but that does not fit into any of the existing SDGs and their 169 SDG targets. In this systematic literature review, we only managed to match 51 of the 71 papers in our corpus to the SDGs. We have referred to the 20 remaining papers ( $28 \%$ of the corpus) as "the non-SDG papers" and these papers were furthermore divided into two equally large groups of 10 papers each.

The first group of non-SDG papers present different perspectives on how to perform and evaluate work within Sustainable HCI. These papers do not report on research that directly contributes to any of the SDG targets, but rather to an internal dialogue about how SHCI research could or should be conducted, and it is not possible to match such works to any of the SDGs. However, the second group of papers do engage with issues that are related to sustainability but that do not fit any of the SDGs. This suggests that despite the fact that the SDGs are wide, they might simultaneously be too narrow to include all relevant work. Another possible interpretation is, however, that these papers, while relating to sustainability, perhaps should not be classified as "sustainability papers." A paper about supporting and scaling up sustainability-oriented organisations' work [8] should perhaps primarily be thought of in terms of being a paper about "activism" and "community organisations" (two of the paper's keywords) that only incidentally concerns community organisations that work towards sustainability-oriented change. Such research is important in order to attain sustainability. However, knowledge about how to support and scale-up organisations can be applied to many different organisations, including organisations that have goals that are incompatible with sustainability.

\subsection{SDG 12 considered as a problem}

The strong focus in our corpus on one single SDG, SDG 12, and the associated systems and solutions these papers propose imply that sustainability within the SHCI community to a great extent is interpreted as a matter of negotiating (e.g. decreasing or shifting) individual resource consumption in the home through informed choices or persuasive systems and oftentimes based on eco-feedback and/or eco-visualisation. DiSalvo et al. [23], as well as Knowles et al. [53] also noted that the connection between sustainability and persuasive systems was a major theme in their literature reviews. For Knowles et al. [53], this was furthermore true for both of the corpora analysed, e.g. both for their 122 "recent papers" as well as their 100 "top-cited papers" in SHCI. Further evidence of this focus is that it also is a common denominator in the other pivotal works mentioned in our Related Works ([30], [15], [76] and [54]).

Dourish [24] suggested that the focus on persuasion as a solution to sustainability challenges represents a typical design response of the cultural logic of neoliberalism. In a market economy that frames sustainability as a problem that can be solved by informed individual choices, solutions that are based on for example acting together on a collective level or as citizens at a political and structural level will tend not to be explored or even noticed. While papers about persuasive systems are still published, there are now also papers that contribute to an internal dialogue within SHCI by questioning the focus on persuasion (e.g. [94], [60] and [61]) or that start from theoretical stances that have been introduced to the field, e.g. practice theory (e.g. [100], [56] and [27]).

\subsection{A mismatch between Sustainable HCI and the SDGs?}

This paper has examined the possibility of using the SDG framework to classify and analyse a decade of work in SHCI. Such an exercise can, however, be turned around to test the SDG framework itself - or to scrutinise Sustainable HCI. While others have criticised the SDG framework for not representing a consistent framework without internal contradictions [2, 89], we are here instead interested in the reach of, or the "fit" between the SDGs and SHCI.

As has been shown above, of the 51 papers in our corpus that could be matched to specific SDGs, more than $80 \%$ were matched to a single SDG, SDG 12 ("Responsible Consumption and Production"). This indicates that the research focus that has characterised Sustainable HCI for the last 10 years is very narrow. Does Sustainable HCI really explore the intersection of sustainability and $\mathrm{HCI}$, or does it only explore a narrow sliver of that intersection? If we use the SDGs as a starting point and then look for sustainability within HCI, such an endeavour would take us to many areas beyond (research and papers that self-identifies as) Sustainable HCI. As mentioned above, there are for example numerous HCI papers that could be construed as working towards SDG 3, "Good health and well-being", and its 13 targets ${ }^{10}$ and there are also 15 other SDGs besides SDG 12 and SDG 3.

This presents Sustainable HCI with a quandary. Sustainable HCI could either ignore the SDGs and continue to be a narrow reserve

\footnotetext{
${ }^{10}$ See further https://sdgs.un.org/goals/goal3 (accessed 2021-01-12)
} 
for a specific type of research in the intersection of sustainability and HCI, or, Sustainable HCI could broaden its focus, possibly by inviting other research within HCI to relate to sustainability and to the Sustainable Development Goals. Based on our systematic literature review, we can authoritatively state that Sustainable HCI is generally perceived to primarily concern (particular types of) environmental sustainability. If the concept of sustainability in HCI is instead broadened to encompass the many issues relating to social sustainability (as suggested by the SDGs), then sustainability would indeed be a significant theme within many different areas that HCI is concerned with. It could be the case that a large part of all HCI research could potentially be framed as relating to sustainability and to the UN Sustainable Development Goals.

\subsection{Next steps}

This systematic literature review is based on papers that were published between 2010 and 2019 and that self-identify as contributing to the field of Sustainable HCI. We have made many choices as part of our study, and the results could differ had we made other choices. One choice we made was to only include peer-reviewed journal articles and conference papers. Another choice was to only include papers that self-identify as "Sustainable HCI", and this means that papers that do work on sustainability issues but that fail to use certain specific terms have been excluded from this review.

Despite these stringent methodological choices, we believe that this paper is the first attempt to systematically explore, map and reflect on how the UN Sustainable Development Goals can be used within HCI. While we have used the SDGs to exclusively look at Sustainable HCI papers, we encourage others to map and analyse other corpora against the SDGs. It would, for example, be interesting to explore papers in the intersection of HCI and ICTs for Development (ICTD), including HCIxB (HCI across borders), or to match papers about HCI4Health against SDG 3, "Good health and well-being", and its sub-goals ("targets" and "indicators"). Such a mapping would both examine what has and what hasn't been done in $\mathrm{HCI}$ and also highlight opportunities for further research. Other examples of SDGs that are highly relevant to HCI are SDG 4, "Quality education", SDG 5, "Gender equality", SDG 10, "Reduced inequalities" and SDG 11, "Sustainable cities and communities". Since ideas for further research would be generated by the SDGs and their targets rather than from within HCI, it is possible that such research would necessitate cooperation with researchers from other academic disciplines outside of HCI.

\section{CONCLUSION}

In this paper, we presented the results of a systematic literature review of peer-reviewed papers and journal articles that have been published in the field of Sustainable HCI (SHCI) during the last ten years (2010-2019). We have applied the United Nations' Sustainable Development Goals (SDGs) as a framework to classify and discern high-level goals that HCI researchers have worked towards. The results obtained contribute to $\mathrm{HCI}$ by 1 ) identifying Sustainable Development Goals that SHCI researchers have worked towards, 2) discerning main research trends in the field during the last decade, 3) using the SDG framework generatively to enumerate and reflect on areas that this far have not been covered by SHCI research and
4) presenting takeaways and opportunities for further research by the larger HCI community.

\section{ACKNOWLEDGMENTS}

Many thanks to Hanna Hasselqvist, Cecilia Katzeff and the anonymous reviewers for helpful comments and constructive feedback on earlier versions of this paper.

\section{REFERENCES}

[1] Arman Arakelyan and David Lamas. 2013. Facilitation of Sustainability through Appropriation-Enabling Design. In Proceedings of the International Conference on Multimedia, Interaction, Design and Innovation (Warsaw, Poland) (MIDI '13). Association for Computing Machinery, New York, NY, USA, Article 5, 9 pages. https://doi.org/10.1145/2500342.2500347

[2] Ranjula Bali Swain. 2017. A Critical Analysis of the Sustainable Development Goals. Springer, Cham, Cham, Switzerland, 341-355. https://doi.org/10.1007/978-3319-63007-6_20

[3] Jeffrey Bardzell. 2009. Interaction Criticism and Aesthetics. In Proceedings of the SIGCHI Conference on Human Factors in Computing Systems (Boston, MA, USA) (CHI '09). Association for Computing Machinery, New York, NY, USA, 2357-2366. https://doi.org/10.1145/1518701.1519063

[4] Mary Barreto, Evangelos Karapanos, and Nuno Nunes. 2011. Social Translucence as a Theoretical Framework for Sustainable HCI. In Proceedings of the 13th IFIP TC 13 International Conference on Human-Computer Interaction - Volume Part IV (Lisbon, Portugal) (INTERACT'11). Springer-Verlag, Berlin, Heidelberg, 195-203.

[5] Oliver Bates, Mike Hazas, Adrian Friday, Janine Morley, and Adrian K. Clear. 2014. Towards an Holistic View of the Energy and Environmental Impacts of Domestic Media and IT. In Proceedings of the SIGCHI Conference on Human Factors in Computing Systems (Toronto, Ontario, Canada) (CHI '14). Association for Computing Machinery, New York, NY, USA, 1173-1182. https://doi.org/10. $1145 / 2556288.2556968$

[6] Avit Bhowmik, Mark McCaffrey, Abigail Ruskey, Chad Frischmann, and Owen Gaffney. 2020. Powers of 10: Seeking 'sweet spots' for rapid climate and sustainability actions between individual and global scales. Environmental Research Letters 15, 9 (06 2020). https://doi.org/10.1088/1748-9326/ab9ed0

[7] A. K. Bhuie, O. A. Ogunseitan, J.-D. M. Saphores, and A. A. Shapiro. 2004. Environmental and Economic Trade-Offs in Consumer Electronic Products Recycling: A Case Study of Cell Phones and Computers. In Proceedings of the International Symposium on Electronics and the Environment (ISEE '04). IEEE Computer Society, USA, 74-79.

[8] Aksel Biørn-Hansen and Maria Håkansson. 2018. Building Momentum: Scaling up Change in Community Organizations. In Proceedings of the $2018 \mathrm{CHI}$ Conference on Human Factors in Computing Systems (Montreal QC, Canada) (CHI '18). Association for Computing Machinery, New York, NY, USA, 1-13. https://doi.org/10.1145/3173574.3173984

[9] Eli Blevis. 2007. Sustainable Interaction Design: Invention \& Disposal, Renewal \& Reuse. In Proceedings of the SIGCHI Conference on Human Factors in Computing Systems (San Jose, California, USA) (CHI '07). Association for Computing Machinery, New York, NY, USA, 503-512. https://doi.org/10.1145/1240624.1240705

[10] Eli Blevis, Chris Preist, Daniel Schien, and Priscilla Ho. 2017. Further Connecting Sustainable Interaction Design with Sustainable Digital Infrastructure Design. In Proceedings of the 2017 Workshop on Computing Within Limits (Santa Barbara, California, USA) (LIMITS '17). Association for Computing Machinery, New York, NY, USA, 71-83. https://doi.org/10.1145/3080556.3080568

[11] Andy Boucher, David Cameron, and Nadine Jarvis. 2012. Power to the People: Dynamic Energy Management through Communal Cooperation. In Proceedings of the Designing Interactive Systems Conference (Newcastle Upon Tyne, United Kingdom) (DIS '12). Association for Computing Machinery, New York, NY, USA, 612-620. https://doi.org/10.1145/2317956.2318048

[12] Anne E. Bowser, Oliver L. Haimson, Edward F. Melcer, and Elizabeth F. Churchill. 2015. On Vintage Values: The Experience of Secondhand Fashion Reacquisition. In Proceedings of the 33rd Annual ACM Conference on Human Factors in Computing Systems (Seoul, Republic of Korea) (CHI '15). Association for Computing Machinery, New York, NY, USA, 897-906. https://doi.org/10.1145/2702123.2702394

[13] Loove Broms, Cecilia Katzeff, Magnus Bång, Åsa Nyblom, Sara Ilstedt Hjelm, and Karin Ehrnberger. 2010. Coffee Maker Patterns and the Design of Energy Feedback Artefacts. In Proceedings of the 8th ACM Conference on Designing Interactive Systems (Aarhus, Denmark) (DIS '10). Association for Computing Machinery, New York, NY, USA, 93-102. https://doi.org/10.1145/1858171.1858191

[14] Gro Bruntland et al. 1987. Our common future. Oxford University Press, Oxford. 45-65 pages.

[15] Hronn Brynjarsdottir, Maria Håkansson, James Pierce, Eric Baumer, Carl DiSalvo, and Phoebe Sengers. 2012. Sustainably Unpersuaded: How Persuasion Narrows Our Vision of Sustainability. In Proceedings of the SIGCHI Conference on Human 
Factors in Computing Systems (Austin, Texas, USA) (CHI '12). Association for Computing Machinery, New York, NY, USA, 947-956. https://doi.org/10.1145/ 2207676.2208539

[16] Hronn Brynjarsdottir, Maria Håkansson, James Pierce, Eric Baumer, Carl DiSalvo, and Phoebe Sengers. 2012. Sustainably Unpersuaded: How Persuasion Narrows Our Vision of Sustainability. In Proceedings of the SIGCHI Conference on Human Factors in Computing Systems (Austin, Texas, USA) (CHI '12). Association for Computing Machinery, New York, NY, USA, 947-956. https://doi.org/10.1145/ 2207676.2208539

[17] Ana Caraban, Evangelos Karapanos, Daniel Gonçalves, and Pedro Campos. 2019 23 Ways to Nudge: A Review of Technology-Mediated Nudging in HumanComputer Interaction. In Proceedings of the 2019 CHI Conference on Human Factors in Computing Systems (Glasgow, Scotland Uk) (CHI '19). Association for Computing Machinery, New York, NY, USA, 1-15. https://doi.org/10.1145/ 3290605.3300733

[18] Teresa Cerratto-Pargman, Daniel Pargman, and Bonnie Nardi. 2016. The Internet at the eco-village: Performing sustainability in the twenty-first century. First Monday 21, 5 (2016)

[19] Rob Comber and Anja Thieme. 2013. Designing beyond Habit: Opening Space for Improved Recycling and Food Waste Behaviors through Processes of Persuasion, Social Influence and Aversive Affect. Personal Ubiquitous Comput. 17, 6 (Aug. 2013), 1197-1210. https://doi.org/10.1007/s00779-012-0587-1

[20] Enrico Costanza, Sarvapali D. Ramchurn, and Nicholas R. Jennings. 2012. Under standing Domestic Energy Consumption through Interactive Visualisation: A Field Study. In Proceedings of the 2012 ACM Conference on Ubiquitous Computing (Pittsburgh, Pennsylvania) (UbiComp '12). Association for Computing Machinery, New York, NY, USA, 216-225. https://doi.org/10.1145/2370216.2370251

[21] Vânia Paula de Almeida Neris, Kamila Rios da Hora Rodrigues, and Renata Firmino Lima. 2014. A systematic review of sustainability and aspects of human-computer interaction. In International Conference on Human-Computer Interaction. Springer, Springer, Cham, Cham, Switzerland, 742-753.

[22] UN Desa et al. 2016. Transforming our world: The 2030 agenda for sustainable development. Technical Report. UN General Assembly, New York, NY, USA.

[23] Carl DiSalvo, Phoebe Sengers, and Hrönn Brynjarsdóttir. 2010. Mapping the Landscape of Sustainable HCI. In Proceedings of the SIGCHI Conference on Human Factors in Computing Systems (Atlanta, Georgia, USA) (CHI '10). Association for Computing Machinery, New York, NY, USA, 1975-1984. https://doi.org/10. 1145/1753326.1753625

[24] Paul Dourish. 2010. HCI and Environmental Sustainability: The Politics of Design and the Design of Politics. In Proceedings of the 8th ACM Conference on Designing Interactive Systems (Aarhus, Denmark) (DIS '10). Association for Computing Machinery, New York, NY, USA, 1-10. https://doi.org/10.1145/ 1858171.1858173

[25] John S Dryzek. 2005. The politics of the earth : environmental discourses. Oxford University Press, Oxford.

[26] Callum Egan, Richard Thompson, and Andrew O’Dowd. 2019. The Lions' Gate Towards a Permaculture-Inspired Blended Space. In Proceedings of the Fifth Workshop on Computing within Limits (Lappeenranta, Finland) (LIMITS '19). Association for Computing Machinery, New York, NY, USA, Article 7, 8 pages. https://doi.org/10.1145/3338103.3338110

[27] Johanne Mose Entwistle, Mia Kruse Rasmussen, Nervo Verdezoto, Robert S. Brewer, and Mads Schaarup Andersen. 2015. Beyond the Individual: The Con textual Wheel of Practice as a Research Framework for Sustainable HCI. In Proceedings of the 33rd Annual ACM Conference on Human Factors in Computing Systems (Seoul, Republic of Korea) (CHI '15). Association for Computing Machinery, New York, NY, USA, 1125-1134. https://doi.org/10.1145/2702123.2702232

[28] Elina Eriksson, Daniel Pargman, Oliver Bates, Maria Normark, Jan Gulliksen, Mikael Anneroth, and Johan Berndtsson. 2016. HCI and UN's Sustainable Development Goals: Responsibilities, Barriers and Opportunities. In Proceedings of the 9th Nordic Conference on Human-Computer Interaction (Gothenburg, Sweden) (NordiCHI '16). Association for Computing Machinery, New York, NY, USA Article 140, 2 pages. https://doi.org/10.1145/2971485.2987679

[29] Ylva Fernaeus, Martin Jonsson, and Jakob Tholander. 2012. Revisiting the Jacquard Loom: Threads of History and Current Patterns in HCI. In Proceedings of the SIGCHI Conference on Human Factors in Computing Systems (Austin, Texas, USA) (CHI '12). Association for Computing Machinery, New York, NY, USA, 1593-1602. https://doi.org/10.1145/2207676.2208280

[30] Jon Froehlich, Leah Findlater, and James Landay. 2010. The Design of EcoFeedback Technology. In Proceedings of the SIGCHI Conference on Human Factors in Computing Systems (Atlanta, Georgia, USA) (CHI '10). Association for Computing Machinery, New York, NY, USA, 1999-2008. https://doi.org/10.1145/ 1753326.1753629

[31] Silke Gegenbauer and Elaine M. Huang. 2012. Inspiring the Design of LongerLived Electronics through an Understanding of Personal Attachment. In Proceedings of the Designing Interactive Systems Conference (Newcastle Upon Tyne, United Kingdom) (DIS '12). Association for Computing Machinery, New York, NY, USA, 635-644. https://doi.org/10.1145/2317956.2318052

[32] Elizabeth Goodman. 2009. Three Environmental Discourses in HumanComputer Interaction. In CHI '09 Extended Abstracts on Human Factors in
Computing Systems. Association for Computing Machinery, New York, NY, USA, 2535-2544. https://doi.org/10.1145/1520340.1520358

[33] Anton Gustafsson and Magnus Gyllenswärd. 2005. The Power-Aware Cord: Energy Awareness through Ambient Information Display. In CHI '05 Extended Abstracts on Human Factors in Computing Systems (Portland, OR, USA) (CHI $E A$ '05). Association for Computing Machinery, New York, NY, USA, 1423-1426. https://doi.org/10.1145/1056808.1056932

[34] Alexa M. Harris, Diego Gómez-Zará, Leslie A. DeChurch, and Noshir S. Contractor. 2019. Joining Together Online: The Trajectory of CSCW Scholarship on Group Formation. Proc. ACM Hum.-Comput. Interact. 3, CSCW, Article 148 (Nov. 2019), 27 pages. https://doi.org/10.1145/3359250

[35] Hanna Hasselqvist, Cristian Bogdan, and Filip Kis. 2016. Linking Data to Action: Designing for Amateur Energy Management. In Proceedings of the 2016 ACM Conference on Designing Interactive Systems (Brisbane, QLD, Australia) (DIS '16). Association for Computing Machinery, New York, NY, USA, 473-483. https: //doi.org/10.1145/2901790.2901837

[36] Hanna Hasselqvist and Elina Eriksson. 2018. Designing for Diverse Stakeholder Engagement in Resource-Intensive Practices. In Proceedings of the 10th Nordic Conference on Human-Computer Interaction (Oslo, Norway) (NordiCHI '18). Association for Computing Machinery, New York, NY, USA, 426-438. https://doi.org/10.1145/3240167.3240193

[37] Hanna Hasselqvist, Mia Hesselgren, and Cristian Bogdan. 2016. Challenging the Car Norm: Opportunities for ICT to Support Sustainable Transportation Practices. In Proceedings of the 2016 CHI Conference on Human Factors in Computing Systems (San Jose, California, USA) (CHI'16). Association for Computing Machinery, New York, NY, USA, 1300-1311. https://doi.org/10.1145/2858036.2858468

[38] Mike Hazas and Lisa Nathan. 2017. Digital Technology and Sustainability: Engaging the Paradox. Routledge, New York, NY, USA.

[39] Sara Heitlinger, Nick Bryan-Kinns, and Janis Jefferies. 2013. Sustainable HCI for Grassroots Urban Food-Growing Communities. In Proceedings of the 25th Australian Computer-Human Interaction Conference: Augmentation, Application, Innovation, Collaboration (Adelaide, Australia) ( $\mathrm{OzCHI}$ '13). Association for Computing Machinery, New York, NY, USA, 255-264. https:/doi.org/10.1145/ 2541016.2541023

[40] Hrönn Brynjarsdóttir Holmer, Carl DiSalvo, Phoebe Sengers, and Thomas Lodato. 2015. Constructing and Constraining Participation in Participatory Arts and HCI. Int. 7. Hum.-Comput. Stud. 74, C (Feb. 2015), 107-123. https: //doi.org/10.1016/j.ijhcs.2014.10.003

[41] Maria Håkansson and Phoebe Sengers. 2013. Beyond Being Green: Simple Living Families and ICT. In Proceedings of the SIGCHI Conference on Human Factors in Computing Systems (Paris, France) (CHI '13). Association for Computing Machinery, New York, NY, USA, 2725-2734. https://doi.org/10.1145/2470654. 2481378

[42] Maria Håkansson and Phoebe Sengers. 2014. No Easy Compromise: Sustainability and the Dilemmas and Dynamics of Change. In Proceedings of the 2014 Conference on Designing Interactive Systems (Vancouver, BC, Canada) (DIS '14). Association for Computing Machinery, New York, NY, USA, 1025-1034. https://doi.org/10.1145/2598510.2598569

[43] Alexander Ilic, Thorsten Staake, and Elgar Fleisch. 2009. Using Sensor Information to Reduce the Carbon Footprint of Perishable Goods. IEEE Pervasive Computing 8, 1 (Jan. 2009), 22-29. https://doi.org/10.1109/MPRV.2009.20

[44] Rachel Jacobs, Steve Benford, Ewa Luger, and Candice Howarth. 2016. The Prediction Machine: Performing Scientific and Artistic Process. In Proceedings of the 2016 ACM Conference on Designing Interactive Systems (Brisbane, QLD, Australia) (DIS '16). Association for Computing Machinery, New York, NY, USA, 497-508. https://doi.org/10.1145/2901790.2901825

[45] Ravi Jain and John Wullert. 2002. Challenges: Environmental Design for Pervasive Computing Systems. In Proceedings of the 8th Annual International Conference on Mobile Computing and Networking (Atlanta, Georgia, USA) (MobiCom '02). Association for Computing Machinery, New York, NY, USA, 263-270. https://doi.org/10.1145/570645.570678

[46] Rikke Hagensby Jensen, Jesper Kjeldskov, and Mikael B. Skov. 2016. HeatDial: Beyond User Scheduling in Eco-Interaction. In Proceedings of the 9th Nordic Conference on Human-Computer Interaction (Gothenburg, Sweden) (NordiCHI '16). Association for Computing Machinery, New York, NY, USA, Article 74, 10 pages. https://doi.org/10.1145/2971485.2971525

[47] Rikke Hagensby Jensen, Jesper Kjeldskov, and Mikael B. Skov. 2018. Assisted Shifting of Electricity Use: A Long-Term Study of Managing Residential Heating. ACM Trans. Comput.-Hum. Interact. 25, 5, Article 25 (Oct. 2018), 33 pages. https: //doi.org/10.1145/3210310

[48] Rikke Hagensby Jensen, Dimitrios Raptis, Jesper Kjeldskov, and Mikael B. Skov. 2018. Washing with the Wind: A Study of Scripting towards Sustainability. In Proceedings of the 2018 Designing Interactive Systems Conference (Hong Kong, China) (DIS '18). Association for Computing Machinery, New York, NY, USA, 1387-1400. https://doi.org/10.1145/3196709.3196779

[49] Somya Joshi and Teresa Cerratto Pargman. 2015. In Search of Fairness: Critical Design Alternatives for Sustainability. In Proceedings of The Fifth Decennial 
Aarhus Conference on Critical Alternatives (Aarhus, Denmark) (CA '15). Aarhus University Press, Aarhus N, 37-40. https://doi.org/10.7146/aahcc.v1i1.21301

[50] Somya Joshi and Teresa Cerratto Pargman. 2015/09. On fairness \& sustainability: Motivating change in the networked society. In Proceedings of EnviroInfo and ICT for Sustainability 2015. Atlantis Press, Paris, France, 335-344. https://doi. org/10.2991/ict4s-env-15.2015.38

[51] Cecilia Katzeff, Loove Broms, Li Jönsson, Ulrika Westholm, and Minna Räsänen 2013. Exploring sustainable practices in workplace settings through visualizing electricity consumption. ACM Transactions on Computer-Human Interaction (TOCHI) 20, 5 (2013), 1-22.

[52] Bran Knowles, Oliver Bates, and Maria Håkansson. 2018. This Changes Sustainable HCI. In Proceedings of the 2018 CHI Conference on Human Factors in Computing Systems (Montreal QC, Canada) (CHI '18). Association for Computing Machinery, New York, NY, USA, 1-12. https://doi.org/10.1145/3173574.3174045

[53] Bran Knowles, Lynne Blair, Mike Hazas, and Stuart Walker. 2013. Exploring Sustainability Research in Computing: Where We Are and Where We Go Next. In Proceedings of the 2013 ACM International foint Conference on Pervasive and Ubiquitous Computing (Zurich, Switzerland) (UbiComp '13). Association for Computing Machinery, New York, NY, USA, 305-314. https://doi.org/10.1145/ 2493432.2493474

[54] Bran Knowles, Lynne Blair, Stuart Walker, Paul Coulton, Lisa Thomas, and Louise Mullagh. 2014. Patterns of Persuasion for Sustainability. In Proceedings of the 2014 Conference on Designing Interactive Systems (Vancouver, BC, Canada) (DIS '14). Association for Computing Machinery, New York, NY, USA, 1035-1044. https://doi.org/10.1145/2598510.2598536

[55] Bran Knowles, Lynne Blair, Stuart Walker, Paul Coulton, Lisa Thomas, and Louise Mullagh. 2014. Patterns of Persuasion for Sustainability. In Proceedings of the 2014 Conference on Designing Interactive Systems (Vancouver, BC, Canada) (DIS '14). Association for Computing Machinery, New York, NY, USA, 1035-1044. https://doi.org/10.1145/2598510.2598536

[56] Lenneke Kuijer, Annelise de Jong, and Daan van Eijk. 2013. Practices as a Unit of Design: An Exploration of Theoretical Guidelines in a Study on Bathing. ACM Trans. Comput.-Hum. Interact. 20, 4, Article 21 (Sept. 2013), 22 pages. https://doi.org/10.1145/2493382

[57] Neha Kumar, Vikram Kamath Cannanure, Dilrukshi Gamage, Annu Sible Prabhakar, Christian Sturm, Cuauhtémoc Rivera Loaiza, Dina Sabie, Md. Moinuddin Bhuiyan, and Mario A. Moreno Rocha. 2020. HCI Across Borders and Sustainable Development Goals. In Extended Abstracts of the 2020 CHI Conference on Human Factors in Computing Systems (Honolulu, HI, USA) (CHI EA '20). Association for Computing Machinery, New York, NY, USA, 1-8. https://doi.org/10.1145/3334480.3375067

[58] Stacey Kuznetsov and Eric Paulos. 2010. UpStream: Motivating Water Conservation with Low-Cost Water Flow Sensing and Persuasive Displays. In Proceedings of the SIGCHI Conference on Human Factors in Computing Systems (Atlanta, Georgia, USA) (CHI '10). Association for Computing Machinery, New York, NY, USA, 1851-1860. https://doi.org/10.1145/1753326.1753604

[59] Ann Light, Eric Kasper, and Sabine Hielscher. 2020. Wicked Solutions: SDGs, Research Design and the "Unfinishedness" of Sustainability. $n / a \mathrm{n} / \mathrm{a}, \mathrm{n} / \mathrm{a}(2020)$ https://doi.org/10.31235/osf.io/m948c

[60] Szu-Yu (Cyn) Liu, Shaowen Bardzell, and Jeffrey Bardzell. 2018. Out of Control Reframing Sustainable HCI Using Permaculture. In Proceedings of the 2018 Workshop on Computing within Limits (Toronto, Ontario, Canada) (LIMITS '18). Association for Computing Machinery, New York, NY, USA, Article 2, 8 pages. https://doi.org/10.1145/3232617.3232625

[61] Szu-Yu (Cyn) Liu, Shaowen Bardzell, and Jeffrey Bardzell. 2019. Symbiotic Encounters: HCI and Sustainable Agriculture. In Proceedings of the 2019 CHI Conference on Human Factors in Computing Systems (Glasgow, Scotland Uk) (CHI '19). Association for Computing Machinery, New York, NY, USA, 1-13. https://doi.org/10.1145/3290605.3300547

[62] Carolynne Lord, Mike Hazas, Adrian K. Clear, Oliver Bates, Rosalind Whittam, Janine Morley, and Adrian Friday. 2015. Demand in My Pocket: Mobile Devices and the Data Connectivity Marshalled in Support of Everyday Practice. In Proceedings of the 33rd Annual ACM Conference on Human Factors in Computing Systems (Seoul, Republic of Korea) (CHI '15). Association for Computing Machinery, New York, NY, USA, 2729-2738. https://doi.org/10.1145/2702123.2702162

[63] Jennifer C. Mankoff, Eli Blevis, Alan Borning, Batya Friedman, Susan R. Fussell, Jay Hasbrouck, Allison Woodruff, and Phoebe Sengers. 2007. Environmental Sustainability and Interaction. In CHI '07 Extended Abstracts on Human Factors in Computing Systems (San Jose, CA, USA) (CHI EA '07). Association for Computing Machinery, New York, NY, USA, 2121-2124. https://doi.org/10.1145/1240866. 1240963

[64] Matthew Louis Mauriello, Brenna McNally, and Jon E. Froehlich. 2019. Thermporal: An Easy-To-Deploy Temporal Thermographic Sensor System to Support Residential Energy Audits. In Proceedings of the 2019 CHI Conference on Human Factors in Computing Systems (Glasgow, Scotland Uk) (CHI '19). Association for Computing Machinery, New York, NY, USA, 1-14. https://doi.org/10.1145/ 3290605.3300343

[65] Matthew Louis Mauriello, Leyla Norooz, and Jon E. Froehlich. 2015. Understanding the Role of Thermography in Energy Auditing: Current Practices and the
Potential for Automated Solutions. In Proceedings of the 33rd Annual ACM Conference on Human Factors in Computing Systems (Seoul, Republic of Korea) (CHI '15). Association for Computing Machinery, New York, NY, USA, 1993-2002. https://doi.org/10.1145/2702123.2702528

[66] Matthew Louis Mauriello, Manaswi Saha, Erica Brown Brown, and Jon E. Froehlich. 2017. Exploring Novice Approaches to Smartphone-Based Thermographic Energy Auditing: A Field Study. In Proceedings of the 2017 CHI Conference on Human Factors in Computing Systems (Denver, Colorado, USA) (CHI '17). Association for Computing Machinery, New York, NY, USA, 1768-1780. https://doi.org/10.1145/3025453.3025471

[67] San Murugesan. 2008. Harnessing green IT: Principles and practices. IT professional 10, 1 (2008), 24-33.

[68] Bonnie Nardi, Bill Tomlinson, Donald J Patterson, Jay Chen, Daniel Pargman, Barath Raghavan, and Birgit Penzenstadler. 2018. Computing within limits. Commun. ACM 61, 10 (2018), 86-93.

[69] Juliet Norton, Ankita Raturi, Bonnie Nardi, Sebastian Prost, Samantha McDonald, Daniel Pargman, Oliver Bates, Maria Normark, Bill Tomlinson, Nico Herbig, et al. 2017. A grand challenge for HCI: food+ sustainability. interactions 24, 6 (2017), 50-55.

[70] C. Okoli. 2015. A Guide to Conducting a Standalone Systematic Literature Review. Commun. Assoc. Inf. Syst. 37 (2015), 43.

[71] Yue Pan and Eli Blevis. 2014. Fashion Thinking: Lessons from Fashion and Sustainable Interaction Design, Concepts and Issues. In Proceedings of the 2014 Conference on Designing Interactive Systems (Vancouver, BC, Canada) (DIS '14). Association for Computing Machinery, New York, NY, USA, 1005-1014. https: //doi.org/10.1145/2598510.2598586

[72] Yue Pan, David Roedl, Eli Blevis, and John Thomas. 2012. Re-Conceptualizing Fashion in Sustainable HCI. In Proceedings of the Designing Interactive Systems Conference (Newcastle Upon Tyne, United Kingdom) (DIS '12). Association for Computing Machinery, New York, NY, USA, 813-815. https://doi.org/10.1145/ 2317956.2318087

[73] Daniel Pargman and Barath Raghavan. 2014. Rethinking Sustainability in Computing: From Buzzword to Non-Negotiable Limits. In Proceedings of the 8th Nordic Conference on Human-Computer Interaction: Fun, Fast, Foundational (Helsinki, Finland) (NordiCHI '14). Association for Computing Machinery, New York, NY, USA, 638-647. https://doi.org/10.1145/2639189.2639228

[74] Petromil Petkov, Suparna Goswami, Felix Köbler, and Helmut Krcmar. 2012. Personalised Eco-Feedback as a Design Technique for Motivating Energy Saving Behaviour at Home. In Proceedings of the 7th Nordic Conference on HumanComputer Interaction: Making Sense Through Design (Copenhagen, Denmark) (NordiCHI '12). Association for Computing Machinery, New York, NY, USA, 587-596. https://doi.org/10.1145/2399016.2399106

[75] Petromil Petkov, Felix Köbler, Marcus Foth, and Helmut Krcmar. 2011. Motivating Domestic Energy Conservation through Comparative, CommunityBased Feedback in Mobile and Social Media. In Proceedings of the 5th International Conference on Communities and Technologies (Brisbane, Australia) (C\&T '11). Association for Computing Machinery, New York, NY, USA, 21-30. https://doi.org/10.1145/2103354.2103358

[76] James Pierce and Eric Paulos. 2012. Beyond Energy Monitors: Interaction, Energy, and Emerging Energy Systems. In Proceedings of the SIGCHI Conference on Human Factors in Computing Systems (Austin, Texas, USA) (CHI '12). Association for Computing Machinery, New York, NY, USA, 665-674. https://doi.org/10.1145/2207676.2207771

[77] James Pierce, Diane J. Schiano, and Eric Paulos. 2010. Home, Habits, and Energy: Examining Domestic Interactions and Energy Consumption. In Proceedings of the SIGCHI Conference on Human Factors in Computing Systems (Atlanta, Georgia, USA) (CHI '10). Association for Computing Machinery, New York, NY, USA, 1985-1994. https://doi.org/10.1145/1753326.1753627

[78] James Pierce, Yolande Strengers, Phoebe Sengers, and Susanne Bødker. 2013. Introduction to the Special Issue on Practice-Oriented Approaches to Sustainable HCI. , 8 pages. https://doi.org/10.1145/2494260

[79] Chris Preist, Daniel Schien, and Eli Blevis. 2016. Understanding and Mitigating the Effects of Device and Cloud Service Design Decisions on the Environmental Footprint of Digital Infrastructure. In Proceedings of the 2016 CHI Conference on Human Factors in Computing Systems (San Jose, California, USA) (CHI '16). Association for Computing Machinery, New York, NY, USA, 1324-1337. https: //doi.org/10.1145/2858036.2858378

[80] Chris Preist, Daniel Schien, and Paul Shabajee. 2019. Evaluating Sustainable Interaction Design of Digital Services: The Case of YouTube. In Proceedings of the 2019 CHI Conference on Human Factors in Computing Systems (Glasgow, Scotland Uk) (CHI '19). Association for Computing Machinery, New York, NY, USA, 1-12. https://doi.org/10.1145/3290605.3300627

[81] Barath Raghavan and Daniel Pargman. 2017. Means and Ends in HumanComputer Interaction: Sustainability through Disintermediation. In Proceedings of the 2017 CHI Conference on Human Factors in Computing Systems (Denver, Colorado, USA) (CHI '17). Association for Computing Machinery, New York, NY, USA, 786-796. https://doi.org/10.1145/3025453.3025542 
[82] Majken K. Rasmussen, Mia Kruse Rasmussen, Nervo Verdezoto, Robert Brewer Laura L. Nielsen, and Niels Olof Bouvin. 2017. Exploring the Flexibility of Everyday Practices for Shifting Energy Consumption through Clockcast. In Proceedings of the 29th Australian Conference on Computer-Human Interaction (Brisbane, Queensland, Australia) (OZCHI '17). Association for Computing Machinery, New York, NY, USA, 296-306. https://doi.org/10.1145/3152771.3152803

[83] Christian Remy, Oliver Bates, Alan Dix, Vanessa Thomas, Mike Hazas, Adrian Friday, and Elaine M. Huang. 2018. Evaluation Beyond Usability: Validating Sustainable HCI Research. In Proceedings of the 2018 CHI Conference on Human Factors in Computing Systems (Montreal QC, Canada) (CHI '18). Association for Computing Machinery, New York, NY, USA, 1-14. https://doi.org/10.1145 3173574.3173790

[84] Christian Remy, Oliver Bates, Vanessa Thomas, and Elaine M. Huang. 2017 The Limits of Evaluating Sustainability. In Proceedings of the 2017 Workshop on Computing Within Limits (Santa Barbara, California, USA) (LIMITS '17). Association for Computing Machinery, New York, NY, USA, 103-110. https: //doi.org/10.1145/3080556.3080567

[85] Christian Remy, Silke Gegenbauer, and Elaine M. Huang. 2015. Bridging the Theory-Practice Gap: Lessons and Challenges of Applying the Attachment Framework for Sustainable HCI Design. In Proceedings of the 33rd Annual ACM Conference on Human Factors in Computing Systems (Seoul, Republic of Korea) (CHI '15). Association for Computing Machinery, New York, NY, USA, 1305-1314. https://doi.org/10.1145/2702123.2702567

[86] Tina Ringenson, Elina Eriksson, Miriam Börjesson Rivera, and Josefin Wangel 2017. The Limits of the Smart Sustainable City. In Proceedings of the 2017 Workshop on Computing Within Limits (Santa Barbara, California, USA) (LIMITS '17). Association for Computing Machinery, New York, NY, USA, 3-9. https: //doi.org/10.1145/3080556.3080559

[87] David Roedl, Shaowen Bardzell, and Jeffrey Bardzell. 2015. Sustainable Making? Balancing Optimism and Criticism in HCI Discourse. ACM Trans. Comput.-Hum Interact. 22, 3, Article 15 (June 2015), 27 pages. https://doi.org/10.1145/2699742

[88] EA Shove, M Hand, J Ingram, and M Watson. 2007. The Design of Everyday Life Berg, Oxford.

[89] Viktoria Spaiser, Shyam Ranganathan, Ranjula Bali Swain, and David JT Sumpter 2017. The sustainable development oxymoron: quantifying and modelling the incompatibility of sustainable development goals. International fournal of Sustainable Development \& World Ecology 24, 6 (2017), 457-470.

[90] Yolande A.A. Strengers. 2011. Designing Eco-Feedback Systems for Everyday Life. In Proceedings of the SIGCHI Conference on Human Factors in Computing Sys tems (Vancouver, BC, Canada) (CHI '11). Association for Computing Machinery, New York, NY, USA, 2135-2144. https://doi.org/10.1145/1978942.1979252

[91] Valerie Sugarman and Edward Lank. 2015. Designing Persuasive Technology to Manage Peak Electricity Demand in Ontario Homes. In Proceedings of the 33rd Annual ACM Conference on Human Factors in Computing Systems (Seoul, Republic of Korea) (CHI '15). Association for Computing Machinery, New York, NY, USA, 1975-1984. https://doi.org/10.1145/2702123.2702364

[92] Theresa Jean Tanenbaum, Marcel Pufal, and Karen Tanenbaum. 2016. The Limits of Our Imagination: Design Fiction as a Strategy for Engaging with Dystopian Futures. In Proceedings of the Second Workshop on Computing within Limits (Irvine, California) (LIMITS '16). Association for Computing Machinery, New York, NY, USA, Article 10, 9 pages. https://doi.org/10.1145/2926676.2926687

[93] Anja Thieme, Rob Comber, Julia Miebach, Jack Weeden, Nicole Kraemer, Shaun Lawson, and Patrick Olivier. 2012. "We've Bin Watching You": Designing for
Reflection and Social Persuasion to Promote Sustainable Lifestyles. In Proceedings of the SIGCHI Conference on Human Factors in Computing Systems (Austin, Texas, USA) (CHI '12). Association for Computing Machinery, New York, NY, USA, 2337-2346. https://doi.org/10.1145/2207676.2208394

[94] Vanessa Thomas, Christian Remy, and Oliver Bates. 2017. The Limits of HCD: Reimagining the Anthropocentricity of ISO 9241-210. In Proceedings of the 2017 Workshop on Computing Within Limits (Santa Barbara, California, USA) (LIMITS '17). Association for Computing Machinery, New York, NY, USA, 85-92. https://doi.org/10.1145/3080556.3080561

[95] Bill Tomlinson, M. Six Silberman, Donald Patterson, Yue Pan, and Eli Blevis. 2012. Collapse Informatics: Augmenting the Sustainability \& ICT4D Discourse in HCI. In Proceedings of the SIGCHI Conference on Human Factors in Computing Systems (Austin, Texas, USA) (CHI '12). Association for Computing Machinery, New York, NY, USA, 655-664. https://doi.org/10.1145/2207676.2207770

[96] Sanna Tuomela, Netta Iivari, and Rauli Svento. 2019. User Values of Smart Home Energy Management System: Sensory Ethnography in VSD Empirical Investigation. In Proceedings of the 18th International Conference on Mobile and Ubiquitous Multimedia (Pisa, Italy) (MUM '19). Association for Computing Machinery, New York, NY, USA, Article 32, 12 pages. https://doi.org/10.1145/ 3365610.3365641

[97] Phil Turner and Susan Turner. 2011. My Grandfather's IPod: An Investigation of Emotional Attachment to Digital and Non-Digital Artefacts. In Proceedings of the 29th Annual European Conference on Cognitive Ergonomics (Rostock, Germany) (ECCE '11). Association for Computing Machinery, New York, NY, USA, 149-156. https://doi.org/10.1145/2074712.2074742

[98] Niels van Berkel, Eleftherios Papachristos, Anastasia Giachanou, Simo Hosio, and Mikael B. Skov. 2020. A Systematic Assessment of National Artificial Intelligence Policies: Perspectives from the Nordics and Beyond. In Proceedings of the 11th Nordic Conference on Human-Computer Interaction: Shaping Experiences, Shaping Society (Tallinn, Estonia) (NordiCHI '20). Association for Computing Machinery, New York, NY, USA, Article 10, 12 pages. https://doi.org/10.1145/ 3419249.3420106

[99] Dhaval Vyas. 2012. Domestic Artefacts: Sustainability in the Context of Indian Middle Class. In Proceedings of the 4th International Conference on Intercultural Collaboration (Bengaluru, India) (ICIC '12). Association for Computing Machinery, New York, NY, USA, 119-128. https://doi.org/10.1145/2160881.2160900

[100] Ron Wakkary, Audrey Desjardins, Sabrina Hauser, and Leah Maestri. 2013. A Sustainable Design Fiction: Green Practices. ACM Trans. Comput.-Hum. Interact. 20, 4, Article 23 (Sept. 2013), 34 pages. https://doi.org/10.1145/2494265

[101] Allison Woodruff, Jay Hasbrouck, and Sally Augustin. 2008. A Bright Green Perspective on Sustainable Choices. In Proceedings of the SIGCHI Conference on Human Factors in Computing Systems (Florence, Italy) (CHI '08). Association for Computing Machinery, New York, NY, USA, 313-322. https://doi.org/10.1145/ 1357054.1357109

[102] Ray Yun, Peter Scupelli, Azizan Aziz, and Vivian Loftness. 2013. Sustainability in the Workplace: Nine Intervention Techniques for Behavior Change. In Proceedings of the 8th International Conference on Persuasive Technology (Sydney, NSW, Australia) (PERSUASIVE'13). Springer-Verlag, Berlin, Heidelberg, 253-265. https://doi.org/10.1007/978-3-642-37157-8 30

[103] Jorge Luis Zapico, Cecilia Katzeff, Ulrica Bohné, and Rebecka Milestad. 2016. Eco-Feedback Visualization for Closing the Gap of Organic Food Consumption. In Proceedings of the 9th Nordic Conference on Human-Computer Interaction (Gothenburg, Sweden) (NordiCHI '16). Association for Computing Machinery, New York, NY, USA, Article 75, 9 pages. https://doi.org/10.1145/2971485.2971507 
Table 3: The SDG papers. Page 1.

\begin{tabular}{|c|c|c|c|c|}
\hline Target & Year & Author & Title & Venue \\
\hline 2.4 & 2015 & Lyle et al. & $\begin{array}{l}\text { Growing Food in the City: Design Ideations for Urban Residential } \\
\text { Gardeners }\end{array}$ & $\mathrm{C} \& \mathrm{~T}$ \\
\hline 2.4 & 2019 & Norton et al. & $\begin{array}{l}\text { Implications of Grassroots Sustainable Agriculture Community Values } \\
\text { on the Design of Information Systems }\end{array}$ & $\mathrm{CSCW}$ \\
\hline 7.1 & 2013 & Bidwell et al. & Walking and the Social Life of Solar Charging in Rural Africa & TOCHI \\
\hline 9.1 & 2012 & $\begin{array}{l}\text { Wyche, P., \& Murphy, } \\
\text { L. }\end{array}$ & $\begin{array}{l}\text { Dead China-make Phones off the Grid: Investigating and Designing } \\
\text { for Mobile Phone Use in Rural Africa }\end{array}$ & DIS \\
\hline 11.3 & 2019 & Heitlinger et al. & The Right to the Sustainable Smart City & $\mathrm{CHI}$ \\
\hline 11.6 & 2017 & Hsu et al. & Community-Empowered Air Quality Monitoring System & $\mathrm{CHI}$ \\
\hline 11.6 & 2019 & Hsu et al. & $\begin{array}{l}\text { Smell Pittsburgh: Community-empowered Mobile Smell Reporting } \\
\text { System }\end{array}$ & IUI \\
\hline 12.2 & 2010 & Pierce et al. & $\begin{array}{l}\text { Home, Habits, and Energy: Examining Domestic Interactions and En- } \\
\text { ergy Consumption }\end{array}$ & $\mathrm{CHI}$ \\
\hline 12.2 & 2011 & Petkov et al. & $\begin{array}{l}\text { Motivating Domestic Energy Conservation Through Comparative, } \\
\text { Community-based Feedback in Mobile and Social Media }\end{array}$ & $\mathrm{C} \& \mathrm{~T}$ \\
\hline 12.2 & 2011 & Strengers, Y. & Designing Eco-feedback Systems for Everyday Life & $\mathrm{CHI}$ \\
\hline 12.2 & 2011 & Barreto et al. & Social Translucence As a Theoretical Framework for Sustainable HCI & INTERACT \\
\hline 12.2 & 2012 & Brynjarsdottir et al. & $\begin{array}{l}\text { Sustainably Unpersuaded: How Persuasion Narrows Our Vision of } \\
\text { Sustainability }\end{array}$ & $\mathrm{CHI}$ \\
\hline 12.2 & 2012 & Boucher et al. & $\begin{array}{l}\text { Power to the People: Dynamic Energy Management Through Commu- } \\
\text { nal Cooperation }\end{array}$ & DIS \\
\hline 12.2 & 2012 & Petkov et al. & $\begin{array}{l}\text { Personalised Eco-feedback As a Design Technique for Motivating En- } \\
\text { ergy Saving Behaviour at Home }\end{array}$ & NordiCHI \\
\hline 12.2 & 2012 & Costanza et al. & $\begin{array}{l}\text { Understanding Domestic Energy Consumption Through Interactive } \\
\text { Visualisation: A Field Study }\end{array}$ & UbiComp \\
\hline 12.2 & 2013 & Yun et al. & $\begin{array}{l}\text { Sustainability in the Workplace: Nine Intervention Techniques for } \\
\text { Behavior Change }\end{array}$ & PERSUASIVE \\
\hline 12.2 & 2014 & Bates et al. & $\begin{array}{l}\text { Towards an Holistic View of the Energy and Environmental Impacts } \\
\text { of Domestic Media and IT }\end{array}$ & $\mathrm{CHI}$ \\
\hline 12.2 & 2014 & Knowles et al. & Patterns of Persuasion for Sustainability & DIS \\
\hline 12.2 & 2015 & Mauriello et al. & $\begin{array}{l}\text { Understanding the Role of Thermography in Energy Auditing: Current } \\
\text { Practices and the Potential for Automated Solutions }\end{array}$ & $\mathrm{CHI}$ \\
\hline 12.2 & 2015 & Lord et al. & $\begin{array}{l}\text { Demand in My Pocket: Mobile Devices and the Data Connectivity } \\
\text { Marshalled in Support of Everyday Practice }\end{array}$ & $\mathrm{CHI}$ \\
\hline 12.2 & 2016 & Priest et al. & $\begin{array}{l}\text { Understanding and Mitigating the Effects of Device and Cloud Service } \\
\text { Design Decisions on the Environmental Footprint of Digital Infrastruc- } \\
\text { ture }\end{array}$ & $\mathrm{CHI}$ \\
\hline 12.2 & 2016 & Hasselqvist et al. & Linking Data to Action: Designing for Amateur Energy Management & DIS \\
\hline
\end{tabular}


Table 4: The SDG papers. Page 2.

\begin{tabular}{|c|c|c|c|c|}
\hline Target & Year & Author & Title & Venue \\
\hline 12.2 & 2016 & Zapico et al. & $\begin{array}{l}\text { Eco-feedback Visualization for Closing the Gap of Organic Food Con- } \\
\text { sumption }\end{array}$ & NordiCHI \\
\hline 12.2 & 2016 & Jensen et al. & HeatDial: Beyond User Scheduling in Eco-Interaction & NordiCHI \\
\hline 12.2 & 2017 & Mauriello et al. & $\begin{array}{l}\text { Exploring Novice Approaches to Smartphone-based Thermographic } \\
\text { Energy Auditing: A Field Study }\end{array}$ & $\mathrm{CHI}$ \\
\hline 12.2 & 2017 & Blevis et al. & $\begin{array}{l}\text { Further Connecting Sustainable Interaction Design with Sustainable } \\
\text { Digital Infrastructure Design }\end{array}$ & LIMITS \\
\hline 12.2 & 2017 & Rasmussen et al. & $\begin{array}{l}\text { Exploring the Flexibility of Everyday Practices for Shifting Energy } \\
\text { Consumption Through Clockcast }\end{array}$ & $\mathrm{OzCHI}$ \\
\hline 12.2 & 2018 & Jensen et al. & Washing with the Wind: A Study of Scripting Towards Sustainability & DIS \\
\hline 12.2 & 2018 & $\begin{array}{l}\text { Hasselqvist, H., \& } \\
\text { Eriksson, E. }\end{array}$ & $\begin{array}{l}\text { Designing for Diverse Stakeholder Engagement in Resource-intensive } \\
\text { Practices }\end{array}$ & NordiCHI \\
\hline 12.2 & 2018 & Jensen et al. & $\begin{array}{l}\text { Assisted Shifting of Electricity Use: A Long-Term Study of Managing } \\
\text { Residential Heating }\end{array}$ & TOCHI \\
\hline 12.2 & 2019 & Priest et al. & $\begin{array}{l}\text { Evaluating Sustainable Interaction Design of Digital Services: The Case } \\
\text { of YouTube }\end{array}$ & $\mathrm{CHI}$ \\
\hline 12.2 & 2019 & Mauriello et al. & $\begin{array}{l}\text { Thermporal: An Easy-To-Deploy Temporal Thermographic Sensor } \\
\text { System to Support Residential Energy Audits }\end{array}$ & $\mathrm{CHI}$ \\
\hline 12.2 & 2019 & Tuomela et al. & Thermporal: User values of smart home energy management system & MUM \\
\hline 12.3 & 2016 & Kuznetsov et al. & $\begin{array}{l}\text { Everyday Food Science As a Design Space for Community Literacy } \\
\text { and Habitual Sustainable Practice }\end{array}$ & $\mathrm{CHI}$ \\
\hline 12.5 & 2011 & $\begin{array}{l}\text { Turner, P., \& Turner, } \\
\text { S. }\end{array}$ & $\begin{array}{l}\text { My Grandfather's iPod: An Investigation of Emotional Attachment to } \\
\text { Digital and Non-digital Artefacts }\end{array}$ & ECCE \\
\hline 12.5 & 2012 & Fernaeus et al. & $\begin{array}{l}\text { Revisiting the Jacquard Loom: Threads of History and Current Patterns } \\
\text { in HCI }\end{array}$ & $\mathrm{CHI}$ \\
\hline 12.5 & 2012 & Thieme et al. & $\begin{array}{l}\text { We'Ve Bin Watching You: Designing for Reflection and Social Persua- } \\
\text { sion to Promote Sustainable Lifestyles }\end{array}$ & $\mathrm{CHI}$ \\
\hline 12.5 & 2012 & Pan et al. & Re-conceptualizing Fashion in Sustainable HCI & DIS \\
\hline 12.5 & 2012 & $\begin{array}{l}\text { Gegenbauer, S., \& } \\
\text { Huang, E. }\end{array}$ & $\begin{array}{l}\text { Inspiring the Design of Longer-lived Electronics Through an Under- } \\
\text { standing of Personal Attachment }\end{array}$ & DIS \\
\hline 12.5 & 2012 & Vyas, D., & $\begin{array}{l}\text { Domestic Artefacts: Sustainability in the Context of Indian Middle } \\
\text { Class }\end{array}$ & ICIC \\
\hline 12.5 & 2013 & $\begin{array}{l}\text { Arakelyan, A., \& } \\
\text { Lamas, D. }\end{array}$ & Facilitation of Sustainability Through Appropriation-enabling Design & MIDI \\
\hline 12.5 & 2013 & $\begin{array}{l}\text { Comber, } \quad \text { R., } \quad \& \\
\text { Thieme, A. }\end{array}$ & $\begin{array}{l}\text { Designing Beyond Habit: Opening Space for Improved Recycling and } \\
\text { Food Waste Behaviors Through Processes of Persuasion, Social Influ- } \\
\text { ence and Aversive Affect }\end{array}$ & Journal \\
\hline 12.5 & 2013 & Wakkary et al. & A Sustainable Design Fiction: Green Practices & TOCHI \\
\hline
\end{tabular}


Table 5: The SDG papers. Page 3.

\begin{tabular}{|c|c|c|c|c|}
\hline Target & Year & Author & Title & Venue \\
\hline 12.5 & 2015 & Remy et al. & $\begin{array}{l}\text { Bridging the Theory-Practice Gap: Lessons and Challenges of Applying } \\
\text { the Attachment Framework for Sustainable HCI Design }\end{array}$ & $\mathrm{CHI}$ \\
\hline 12.5 & 2015 & Bowser et al. & $\begin{array}{l}\text { On Vintage Values: The Experience of Secondhand Fashion Reacquisi- } \\
\text { tion }\end{array}$ & $\mathrm{CHI}$ \\
\hline 12.5 & 2015 & Roedl et al. & $\begin{array}{l}\text { Sustainable Making? Balancing Optimism and Criticism in HCI Dis- } \\
\text { course }\end{array}$ & TOCHI \\
\hline 12.6 & 2014 & $\begin{array}{l}\text { Nyström, T., \& Mus- } \\
\text { taquim, M. }\end{array}$ & $\begin{array}{l}\text { Sustainable Information System Design and the Role of Sustainable } \\
\text { HCI }\end{array}$ & $\begin{array}{l}\text { Academic } \\
\text { MindTrek }\end{array}$ \\
\hline 12.8 & 2013 & $\begin{array}{l}\text { Banerjee, A., \& Horn, } \\
\text { M. }\end{array}$ & $\begin{array}{l}\text { Ghost Hunter: Parents and Children Playing Together to Learn About } \\
\text { Energy Consumption }\end{array}$ & TEI \\
\hline 12.8 & 2016 & $\begin{array}{l}\text { Meyers, E., \& Nathan, } \\
\text { L. }\end{array}$ & $\begin{array}{l}\text { Impoverished Visions of Sustainability: Encouraging Disruption in } \\
\text { Digital Learning Environments }\end{array}$ & $\mathrm{CsCW}$ \\
\hline 13.1 & 2012 & Tomlinson et al. & $\begin{array}{l}\text { Collapse Informatics: Augmenting the Sustainability \& ICT4D Dis- } \\
\text { course in HCI }\end{array}$ & $\mathrm{CHI}$ \\
\hline 13.1 & 2013 & Tomlinson et al. & Collapse Informatics and Practice: Theory, Method, and Design & TOCHI \\
\hline
\end{tabular}


Table 6: The Non-SDG papers. Page 1.

\begin{tabular}{|c|c|c|c|}
\hline Year & Author & Title & Venue \\
\hline 2013 & Kuijer et al. & $\begin{array}{l}\text { Practices As a Unit of Design: An Exploration of Theoretical Guidelines in a } \\
\text { Study on Bathing }\end{array}$ & TOCHI \\
\hline 2013 & $\begin{array}{l}\text { Håkansson, M., \& } \\
\text { Sengers, P. }\end{array}$ & Beyond Being Green: Simple Living Families and ICT & $\mathrm{CHI}$ \\
\hline 2013 & Heitlinger et al. & Sustainable HCI for Grassroots Urban Food-growing Communities & $\mathrm{OzCHI}$ \\
\hline 2014 & $\begin{array}{l}\text { Håkansson, M., \& } \\
\text { Sengers, P. }\end{array}$ & $\begin{array}{l}\text { No Easy Compromise: Sustainability and the Dilemmas and Dynamics of } \\
\text { Change }\end{array}$ & DIS \\
\hline 2014 & $\begin{array}{l}\text { Pargman, D., \& } \\
\text { Raghavan, B. }\end{array}$ & $\begin{array}{l}\text { Rethinking Sustainability in Computing: From Buzzword to Non-negotiable } \\
\text { Limits }\end{array}$ & NordiCH \\
\hline 2014 & Pan, Y., \& Blevis, E. & $\begin{array}{l}\text { Fashion Thinking: Lessons from Fashion and Sustainable Interaction Design, } \\
\text { Concepts and Issues }\end{array}$ & DIS \\
\hline 2015 & Entwistle et al. & $\begin{array}{l}\text { Beyond the Individual: The Contextual Wheel of Practice As a Research } \\
\text { Framework for Sustainable HCI }\end{array}$ & $\mathrm{CHI}$ \\
\hline 2015 & $\begin{array}{l}\text { Brynjarsdóttir } \\
\text { Holmer et al. }\end{array}$ & Constructing and Constraining Participation in Participatory Arts and HCI & Journal \\
\hline 2016 & Jacobs et al. & The Prediction Machine: Performing Scientific and Artistic Process and HCI & DIS \\
\hline 2016 & Tanenbaum et al. & $\begin{array}{l}\text { The Limits of Our Imagination: Design Fiction As a Strategy for Engaging } \\
\text { with Dystopian Futures }\end{array}$ & LIMITS \\
\hline 2016 & Hasselqvist et al. & $\begin{array}{l}\text { Challenging the Car Norm: Opportunities for ICT to Support Sustainable } \\
\text { Transportation Practices }\end{array}$ & $\mathrm{CHI}$ \\
\hline 2017 & $\begin{array}{l}\text { Raghavan, B., \& } \\
\text { Pargman, D. }\end{array}$ & $\begin{array}{l}\text { Means and Ends in Human-Computer Interaction: Sustainability Through } \\
\text { Disintermediation }\end{array}$ & $\mathrm{CHI}$ \\
\hline 2017 & Remy et al. & The Limits of Evaluating Sustainability & LIMITS \\
\hline 2017 & Thomas et al. & The Limits of HCD: Reimagining the Anthropocentricity of ISO 9241-210 & LIMITS \\
\hline 2018 & Remy et al. & Evaluation Beyond Usability: Validating Sustainable HCI Research & $\mathrm{CHI}$ \\
\hline 2018 & Knowles et al. & This Changes Sustainable HCI & $\mathrm{CHI}$ \\
\hline 2018 & Liu et al. & Out of Control: Reframing Sustainable HCI Using Permaculture & LIMITS \\
\hline 2018 & $\begin{array}{l}\text { Biørn-Hansen, A., \& } \\
\text { Håkansson, M. }\end{array}$ & Building Momentum: Scaling Up Change in Community Organizations & $\mathrm{CHI}$ \\
\hline 2019 & Liu et al. & Symbiotic Encounters: HCI and Sustainable Agriculture & $\mathrm{CHI}$ \\
\hline 2019 & Egan et al. & The Lions' Gate: Towards a Permaculture-inspired Blended Space & LIMITS \\
\hline
\end{tabular}

